\title{
Reversible Spin-State Switching and Tuning of Nuclearity and Dimensionality via Nonlinear Pseudohalides in Cobalt(II) Complexes
}

Subrata Ghosh, ${ }^{\mathrm{a}}$ Sujit Kamilya, ${ }^{\mathrm{a}}$ Mathieu Rouzières, ${ }^{\mathrm{b}}$ Radovan Herchel, ${ }^{\mathrm{c}}$ Sakshi Mehta ${ }^{\mathrm{a}}$ and Abhishake Mondal*a

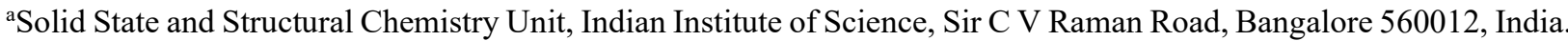

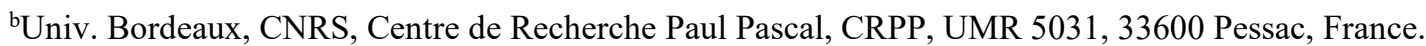

${ }^{\mathrm{c} D e p a r t m e n t ~ o f ~ I n o r g a n i c ~ C h e m i s t r y, ~ F a c u l t y ~ o f ~ S c i e n c e, ~ P a l a c k y ́ ~ U n i v e r s i t y, ~ 17 . ~ l i s t o p a d u ~ 12, ~ C Z-771 ~} 46$ Olomouc, Czech Republic.

Correspondence to: mondal@iisc.ac.in 


\section{Table of Content:}

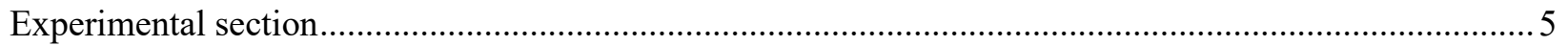

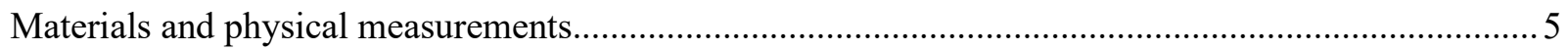

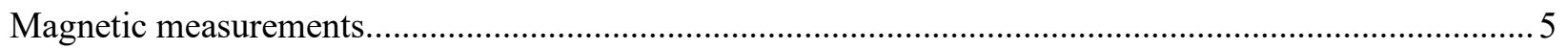

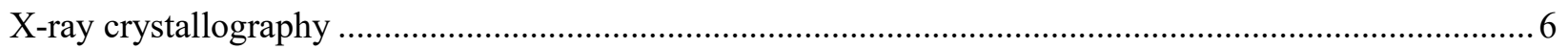

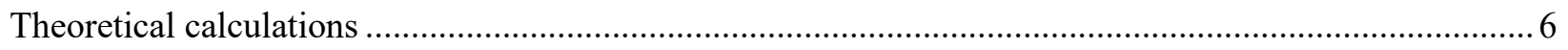

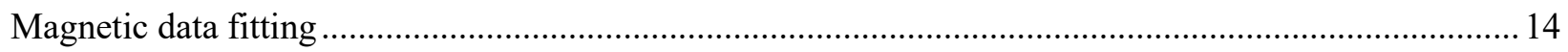

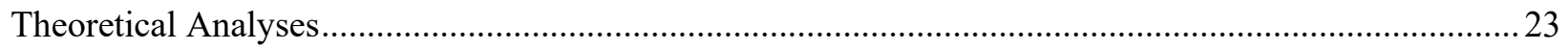

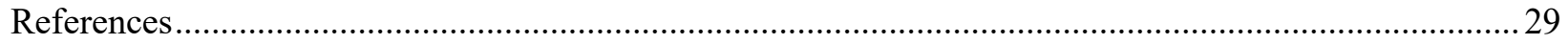

Figure S1 Comparison of the room temperature experimental PXRD pattern and the $296 \mathrm{~K}$ simulated one for 1 .

Figure S2 Comparison of the room temperature experimental PXRD pattern and the $296 \mathrm{~K}$ simulated one

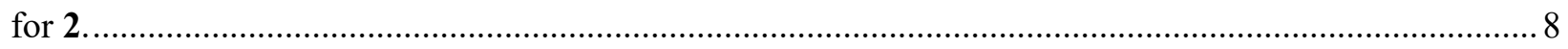

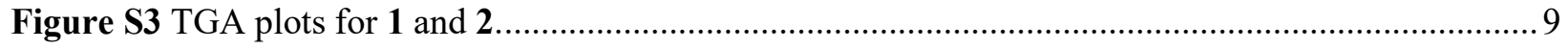

Figure S4 Left: IR spectra of ligand $\mathbf{L}$, complexes $\mathbf{1}$ and $\mathbf{2}$ at room temperature, Right: selected region of

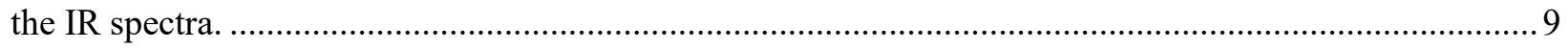

Figure S5 IR spectra of pseudohalides, $\mathrm{Na}\left[\mathrm{N}(\mathrm{CN})_{2}\right]$ (left) and $\mathrm{Na}\left[\mathrm{C}(\mathrm{CN})_{3}\right]$ (right)............................ 10

Figure S6 Top: Thermal ellipsoidal diagrams for the asymmetric units of the crystal structures of 1 (a) and 2 (b) at $296 \mathrm{~K}$. Thermal ellipsoids are drawn at a $25 \%$ probability level. Bottom: Unit cell packing diagram of 2 at $100 \mathrm{~K}$. Hydrogen atoms are omitted for clarity. (Co: pink, C: grey, N: blue; B: light-pink; F: green, O: red) 10

Figure S7 Packing diagrams of 2 at $100 \mathrm{~K}$ showing the 1D supramolecular arrangement (top) and the supramolecular double chain (bottom) connected by $\mathrm{C}-\mathrm{H} \cdots \mathrm{F}$ and $\mathrm{C} \cdots \mathrm{F}$ (red dotted lines) interactions. (Co: pink, C: grey, N: blue; B: light-pink; F: green).

Figure S8 Solid state UV/vis/NIR spectra of $\mathbf{1}$ and $\mathbf{2}$ at RT. 12

Figure S9 UV/vis/NIR spectra of $\mathbf{1}$ and $\mathbf{2}$ in DMF at room temperature (left: dilute solution, right: concentrated solution).

Figure S10. Field dependence of the magnetization as $M v s H$ plots for $\mathbf{1}$ (left) and $\mathbf{2}$ (right) at $100 \mathrm{~K}$. The solid lines are best fit.

Figure S11 Temperature dependence of $\chi T$ product for $\mathbf{1}$ (left: normal Scale, right: log scale).............. 13

Figure S12 Field dependence of the magnetization as $M v s H$ (left) and $M v s H / T$ (right) plots for 1 at 1.85

$\mathrm{K}, 3 \mathrm{~K}, 5 \mathrm{~K}$ and $8 \mathrm{~K}$. The solid lines are guide for the eyes. 
Figure S13 Frequency $(100 \mathrm{~Hz}) v s$ temperature plot of the real $\left(\chi^{\prime}\right.$, left $)$ and imaginary $\left(\chi^{\prime \prime}\right.$, right) components of the ac susceptibility at 0 Oe external de field and different temperatures from $1.8-15 \mathrm{~K}$, respectively with a 3 Oe ac field for a polycrystalline sample of $\mathbf{1}$ 14

Figure S14 Frequency dependence of the real $\left(\chi^{\prime}\right.$, left $)$ and imaginary ( $\chi^{\prime \prime}$, right) parts of the ac susceptibility for a polycrystalline sample of 1 at $2 \mathrm{~K}$ at different dc-field between 0 and 10000 Oe. Solid lines are eye guide.

Figure S15 Magnetic data for 1 showed as temperature dependence of the $\chi T$ product (left) calculated from the molar magnetization measured at $H=0.1 \mathrm{~T}$ shown in the inset, and isothermal magnetizations measured at $T=1.85,3,5$ and $8 \mathrm{~K}$ (right). Empty circles - experimental data, full lines - calculated data with eq. 1 using $D=-72.3 \mathrm{~cm}^{-1}, E / D=0.00, g_{\mathrm{z}}=2.87, g_{\mathrm{xy}}=2.21$ and $z j=-0.273 \mathrm{~cm}^{-1}$.

Figure S16 Magnetic data for 1 showed as temperature dependence of the $\chi T$ product (left) calculated from the molar magnetization measured at $H=0.1 \mathrm{~T}$ shown in the inset, and isothermal magnetizations measured at $T=1.85,3,5$ and $8 \mathrm{~K}$ (right). Empty circles - experimental data, full lines - calculated data with eq. 2 using $\Delta_{\alpha \mathrm{x}}=-1800 \mathrm{~cm}^{-1}, \Delta_{\mathrm{rh}}=-11.6 \mathrm{~cm}^{-1}, \alpha=1.50, \lambda=-135 \mathrm{~cm}^{-1}$ and $z j=-1.93 \mathrm{~cm}^{-1} \ldots$

Figure S17 Temperature dependence of $\chi \mathrm{T}$ product for $\mathbf{2}$ in cooling (blue) and heating (red) modes...... 17

Figure S18 Fitting of $\chi T v s \mathrm{~T}$ data of $\mathbf{2}$ using the ideal solution model................................................ 18

Figure S19 Field dependence of the magnetization as $M$ vs $H$ (left) and $M$ vs $H / T$ (right) plots for 2 at $4 \mathrm{~K}$ and $8 \mathrm{~K}$. The solid lines are guide for the eyes. .18 Figure S20 Cyclic voltammograms for the reduction (left) of $\mathbf{1}$ in $0.2 \mathrm{M}\left({ }^{n} \mathrm{Bu}_{4} \mathrm{~N}\right) \mathrm{PF}_{6} / \mathrm{DMF}$ at various scan rates. Arrows indicate the open circuit potential along with direction of potential sweep.

Figure S21 Square wave voltammograms (oxidation: blue line and reduction: red line) of 1 in $0.2 \mathrm{M}$ $\left({ }^{n} \mathrm{Bu}_{4} \mathrm{~N}\right) \mathrm{PF}_{6} / \mathrm{DMF}$. Arrows indicate the open circuit potential along with direction of potential sweep.... 19 Figure S22 Differential pulse voltammograms (oxidation: blue line and reduction: red line) of 1 in $0.2 \mathrm{M}$ $\left({ }^{n} \mathrm{Bu}_{4} \mathrm{~N}\right) \mathrm{PF}_{6} / \mathrm{DMF}$. Arrows indicate the open circuit potential along with direction of potential sweep.....20 Figure S23 Cyclic voltammograms for the oxidation of 2 in $0.2 \mathrm{M}\left({ }^{n} \mathrm{Bu}_{4} \mathrm{~N}\right) \mathrm{PF}_{6} / \mathrm{DMF}$ at various scan rates. Arrows indicate the open circuit potential along with direction of potential sweep. 20

Figure S24 Square wave voltammogram for oxidation of 2 in $0.2 \mathrm{M}\left({ }^{n} \mathrm{Bu}_{4} \mathrm{~N}\right) \mathrm{PF}_{6} / \mathrm{DMF}$. Arrows indicate the open circuit potential along with direction of potential sweep. .21

Figure S25 Differential pulse voltammogram for reduction of 2 in $0.2 \mathrm{M}\left({ }^{n} \mathrm{Bu}_{4} \mathrm{~N}\right) \mathrm{PF}_{6} / \mathrm{DMF}$. Arrows indicate the open circuit potential along with direction of potential sweep.

Figure S26 Left: Cyclic voltammogram for reduction of 2 in $0.2 \mathrm{M}\left({ }^{n} \mathrm{Bu}_{4} \mathrm{~N}\right) \mathrm{PF}_{6} / \mathrm{DMF}$ with sweep rate of $0.1 \mathrm{~V} / \mathrm{s}$; Right: Selected region $(0.35 \mathrm{~V}-1.2 \mathrm{~V})$ voltammograms with various sweep rates. Arrows indicate the open circuit potential along with direction of potential sweep. 
Figure S27 Cyclic voltammograms for the reduction (left) and oxidation (right) of the tetradentate ligand $\mathbf{L}$ in $0.2 \mathrm{M}\left({ }^{n} \mathrm{Bu}_{4} \mathrm{~N}\right) \mathrm{PF}_{6} / \mathrm{DMF}$ with scan rate of $100 \mathrm{mV} / \mathrm{s}$.

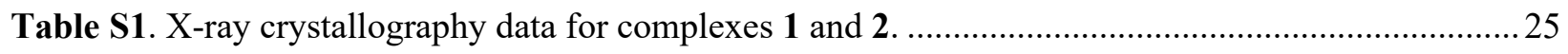

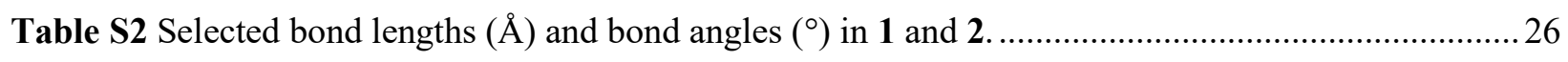

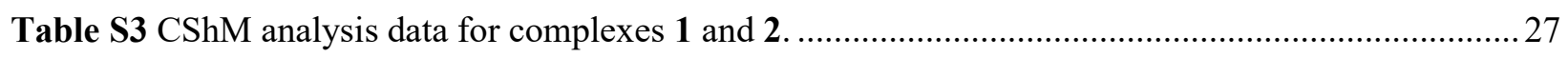

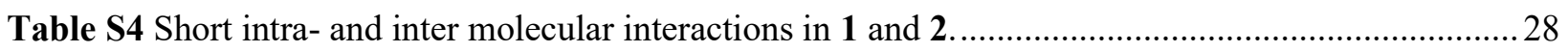




\section{Experimental section}

\section{Materials and physical measurements}

All manipulations were carried out under an argon atmosphere using standard Schlenk techniques unless otherwise stated. Solvents were dried by standard methods and were freshly distilled before to use. All chemicals were used as purchased from the chemical sources without further purification. The macrocyclic ligand $N, N^{\prime}$-di-tert-butyl-2,11-diaza[3,3](2,6) pyridinophane (L) was synthesized according to the literature procedure. ${ }^{1,2}$ The crystals of both complexes were removed from the mother liquor and dried on a filter paper to remove any adhering solvent molecules, prior to measurement. The elemental analyses for $\mathrm{C}, \mathrm{H}$ and N were performed with Thermo Scientific Flash 2000 Organic Elemental Analyzer. Infrared (IR) spectra were recorded in the range of $4000-400 \mathrm{~cm}^{-1}$ on Bruker Tensor 27 spectrometer. UV/vis/NIR spectra were carried out in the region of $250-2000 \mathrm{~nm}$ on a Lambda $750 \mathrm{UV}$-vis-NIR spectrometer. The UV/vis/NIR spectroscopic measurements in solution were done in quartz cuvettes with a path length of 1 $\mathrm{cm}$. Solid-state measurements were carried out by taking approx. 5\% sample by weight in $\mathrm{KBr}$. Thermogravimetric analysis (TGA) was done on a Mettler Toledo TGA/SDTA851 analyzer with a heating rate of $10 \mathrm{~K} \mathrm{~min}^{-1}$ under a nitrogen atmosphere ranging from $300 \mathrm{~K}$ to $675 \mathrm{~K}$ (for $\mathbf{1}$ ) and $300 \mathrm{~K}$ to $775 \mathrm{~K}$

(for 2). Room Temperature Powder X-ray diffraction (PXRD) measurements were carried out on a PANalytical Empyrean diffractometer at $45 \mathrm{kV}$ and $30 \mathrm{~mA}$, under $\mathrm{Cu}-\mathrm{K} \alpha$ radiation $(\lambda=1.54059 \AA)$. PXRD data analyses were done using PANalytical X'Pert HighScore Plus software. ${ }^{3}$ Electrochemistry studies were performed with a Metrohm Autolab PGSTAT101 using platinum as a working electrode, a glassy carbon as counter electrode and a silver chloride $(\mathrm{Ag} / \mathrm{AgCl})$ electrode as the reference electrode in DMF with 0.1 $\mathrm{M}\left({ }^{n} \mathrm{Bu}_{4} \mathrm{~N}\right) \mathrm{PF}_{6}$ as supporting electrolyte. The concentration of the complexes used is around $1 \mathrm{mM}$. The ferrocene/ferrocenium redox couple served as the internal reference $(+0.53 \mathrm{~V}$ vs. $\mathrm{Ag} / \mathrm{AgCl})$.

\section{Magnetic measurements}

The magnetic susceptibility measurements were performed with Quantum Design MPMS-XL and MPMS-XL EverCool SQUID magnetometer between 2-400 K under a $d c$ applied fields ranging from -7 to +7 $\mathrm{T}$ for $\mathbf{1}$ and -5 to $+5 \mathrm{~T}$ for $\mathbf{2}$, respectively. Polycrystalline samples of $\mathbf{1}$ and $\mathbf{2}(13.84 \mathrm{mg}$ and $8.0 \mathrm{mg}$, 
respectively) introduced in a polyethylene bag $(2.8 \times 0.75 \times 0.02 \mathrm{~cm})$ were subjected to measurements. The temperature dependent data were measured using 1000 Oe and 10000 Oe dc field for both $\mathbf{1}$ and $\mathbf{2}$ respectively. The isothermal magnetization data were acquired at 1.85, 3, 5, and $8 \mathrm{~K}$ for 1 and 4 and $8 \mathrm{~K}$ for 2 . The $a c$ susceptibility measurements were performed with an oscillating $a c$ field of 1 to 6 Oe with a frequency between 10 to $10000 \mathrm{~Hz}$ (PPMS-EverCool II) and with an oscillating ac field of 3 Oe with a fixed frequency of $100 \mathrm{~Hz}$ (MPMS-XL) at different temperatures ranging from $15-1.9 \mathrm{~K}$. Frequency dependence was measured at different external $d c$ magnetic field ranging from $0-10000$ Oe at $2 \mathrm{~K} . M v s$ $H$ measurements were performed at $100 \mathrm{~K}$ to check for the presence of ferromagnetic impurities which were found to be absent (Figure S10). The magnetic data were corrected for the sample holder and the diamagnetic contribution.

\section{X-ray crystallography}

Single crystal X-ray structure analysis of the complexes $\mathbf{1}$ and $\mathbf{2}$ were collected with a Bruker SMART APEX CCD diffractometer equipped with graphite monochromated MoK $\alpha$ radiation $(\lambda=0.71073 \AA)$. The single crystal was mounted on a crystal mounting loop with the help of Paratone oil purchased from MiTeGen at $296 \mathrm{~K}$ and then collected the data. For variable temperature measurements, the single crystal was slowly cooled down to the measurement temperature with $2 \mathrm{~K} \mathrm{~min}^{-1}$ ramping rate, followed by data collection at $296 \mathrm{~K}$ (1 and 2) and $100 \mathrm{~K}$ (2). Data integration and reduction were performed with the help of SAINT software and empirical absorption corrections were applied with SADABS programme. ${ }^{4}$ Structures were solved using direct methods and refined with a full-matrix least-squares method on $\mathrm{F}^{2} \mathrm{using}$ SHELXL-2014. ${ }^{5}$ All non-hydrogen atoms were refined using anisotropic displacement parameters. Hydrogen atoms were labeled to ideal positions and refined isotropically using a riding model.

\section{Theoretical calculations}

The ORCA 4.1 computational package was used for quantum chemical calculations. ${ }^{6,7}$ First, binuclear molecular fragments $\left[\mathrm{Co}_{2}(\mathbf{L})_{2}\left(\mathrm{~N}(\mathrm{CN})_{2}\right)_{3}\right]^{+}$of $\mathbf{1}$ and $\left[\mathrm{Co}_{2}(\mathbf{L})_{2}\left(\mathrm{C}(\mathrm{CN})_{3}\right)_{2}\right]^{2+}$ of $\mathbf{2}$ were extracted from X-ray data and the positions of hydrogen atoms were optimized with DFT method using BP86 functional. ${ }^{8}$ Then, 
B3LYP functional ${ }^{8-10}$ was used for calculations of the energies of high-spin (HS) and broken-symmetry spin (BS) states, $\Delta=\varepsilon_{\mathrm{BS}}-\varepsilon_{\mathrm{HS}}$. Next, the isotropic exchange parameters $J$ were computed according to the Yamaguchi method ${ }^{11}$ as

$$
\left.J=2 \Delta /\left[\left\langle S^{2}\right\rangle_{\mathrm{HS}}-\left\langle S^{2}\right\rangle_{\mathrm{BS}}\right)\right]
$$

for spin Hamiltonian of the form

$$
\widehat{H}=-J\left(\vec{S}_{1} \cdot \vec{S}_{2}\right)
$$

The polarized triple- $\zeta$ quality basis set def2-TZVP was used for all atoms except for carbon and hydrogen atoms for which def2-SVP basis set was applied. ${ }^{12}$ The calculations utilized the RI approximation with the decontracted auxiliary def $2 / \mathrm{J}$ Coulomb fitting basis set $^{13}$ and the chain-of-spheres (RIJCOSX) approximation to exact exchange ${ }^{14,15}$ as implemented in ORCA. Increased integration grids (Grid6 and Gridx6 in ORCA convention) and tight SCF convergence criteria were used in all calculations. The calculated spin density was visualized with VESTA 3 program. ${ }^{16}$

Next, the calculations of the zero-field splitting (ZFS) parameters were done using state average complete active space self-consistent field (SA-CASSCF) ${ }^{17}$ wave functions complemented by $N$-electron valence second-order perturbation theory (NEVPT2). ${ }^{18,19}$ In the state-averaged approach all multiplets for given electron configuration were equally weighted. The ZFS parameters, based on dominant spin-orbit coupling contributions from excited states, were calculated through quasi-degenerate perturbation theory (QDPT), ${ }^{20}$ in which an approximation to the Breit-Pauli form of the spin-orbit coupling operator (SOMF approximation $^{21}$ and the effective Hamiltonian theory ${ }^{22}$ were utilized. The calculations utilized the RIJCOSX approximation with the auxiliary basis sets def2/J and def2-TZVP/C. ${ }^{23}$ Increased integration grids (Grid6 and GridX6 in ORCA convention) and tight SCF convergence criteria were used in all calculations. The ab initio ligand field theory (AILFT) was utilized for energy calculations of $d$-orbitals. ${ }^{24,25}$ Moreover, recently introduced dynamic correlation dressed CAS with the second-order treatment (DCDCAS(2)) were also utilized to calculate ZFS parameters as well. ${ }^{26}$ 


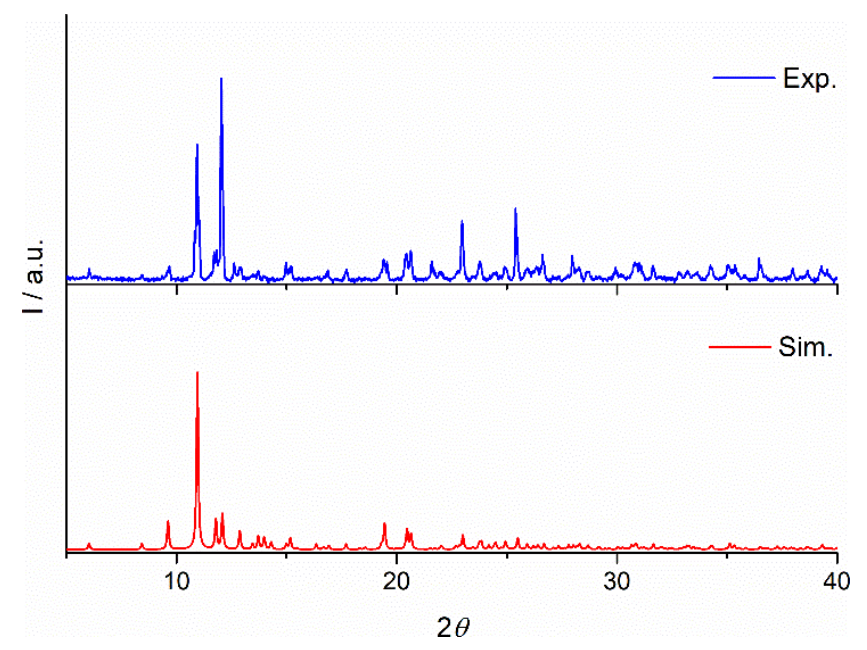

Figure S1 Comparison of the room temperature experimental PXRD pattern and the $296 \mathrm{~K}$ simulated one for 1.

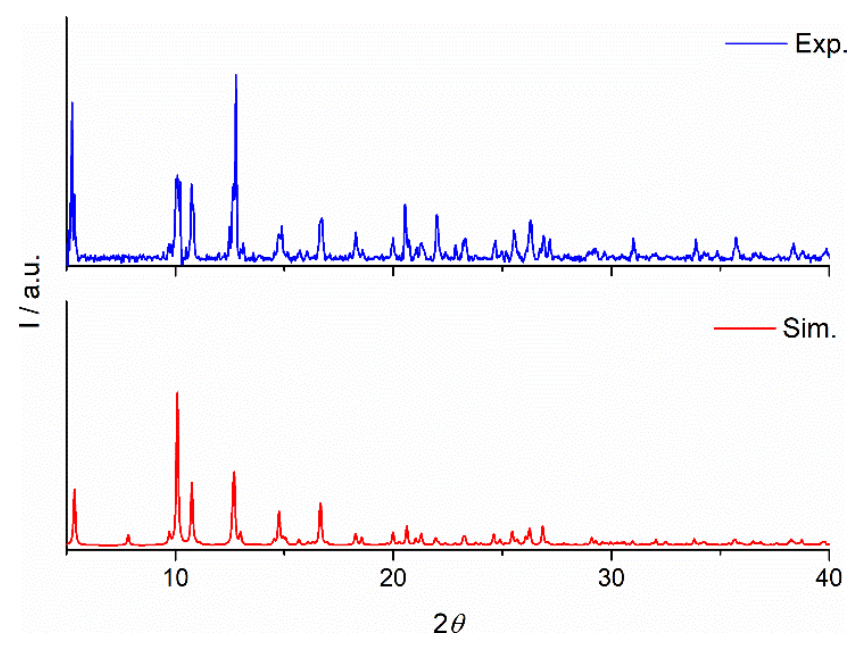

Figure S2 Comparison of the room temperature experimental PXRD pattern and the $296 \mathrm{~K}$ simulated one for 2. 


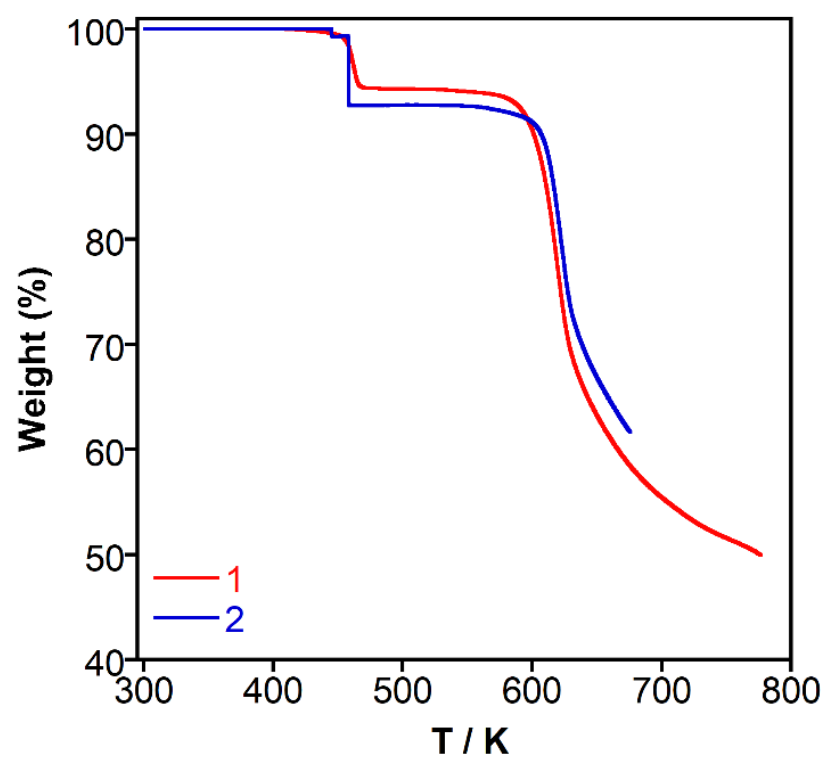

Figure S3 TGA plots for 1 and 2.

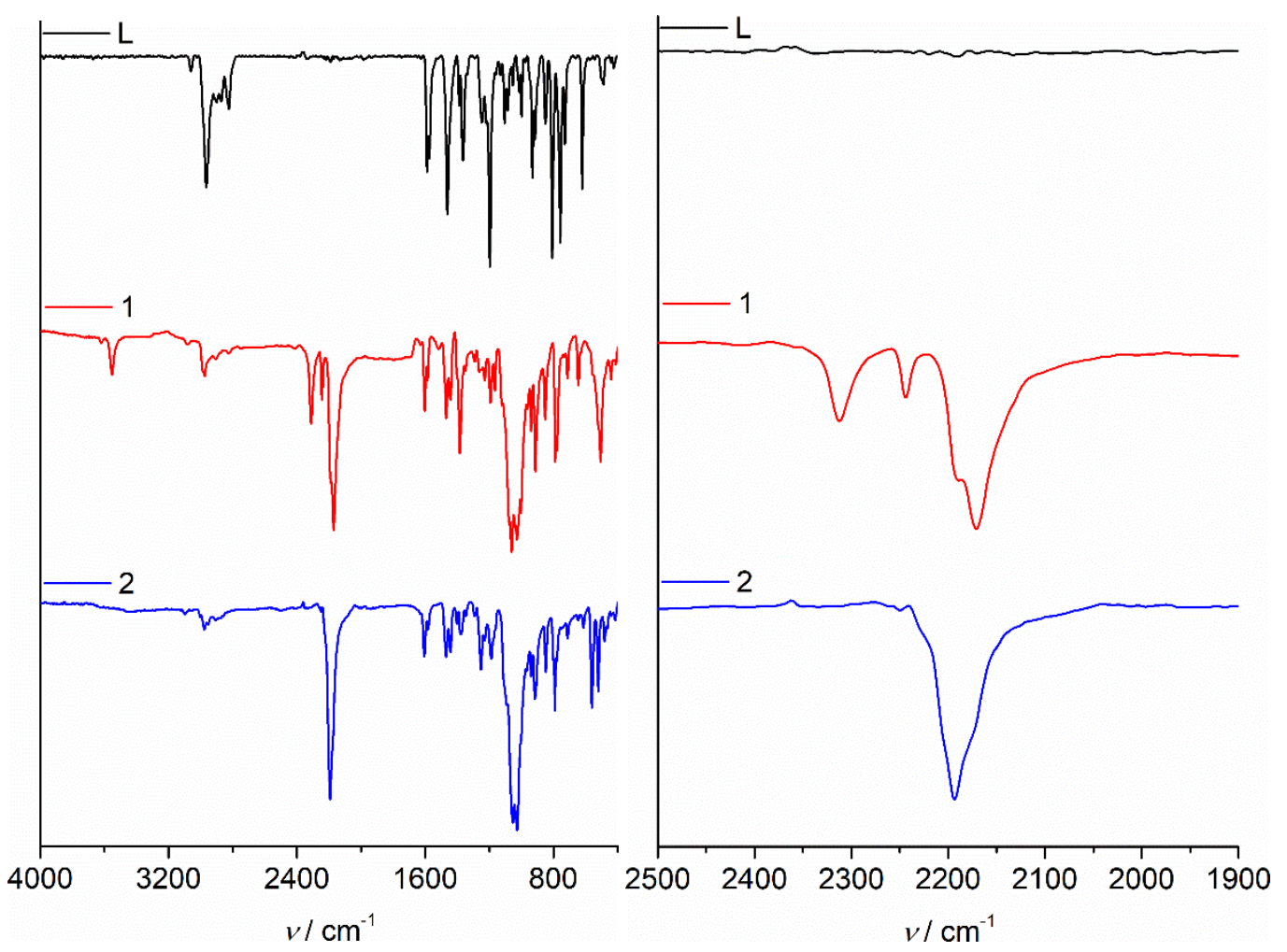

Figure S4 Left: IR spectra of ligand $\mathbf{L}$, complexes $\mathbf{1}$ and $\mathbf{2}$ at room temperature, Right: selected region of the IR spectra. 

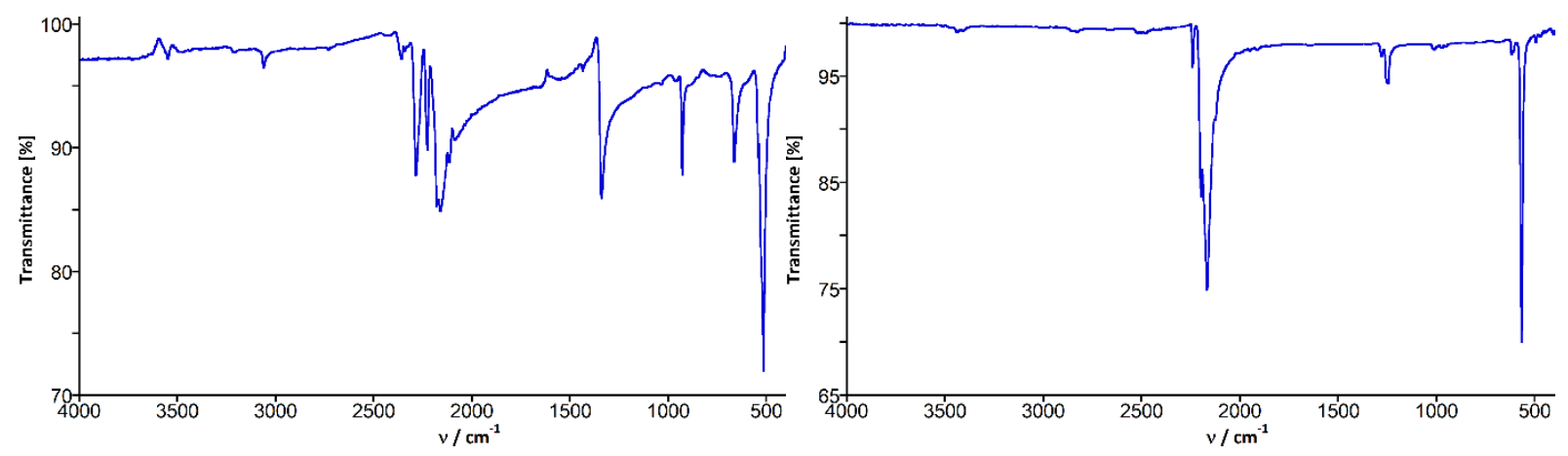

Figure S5 IR spectra of pseudohalides, $\mathrm{Na}\left[\mathrm{N}(\mathrm{CN})_{2}\right]$ (left) and $\mathrm{Na}\left[\mathrm{C}(\mathrm{CN})_{3}\right]$ (right).

a)

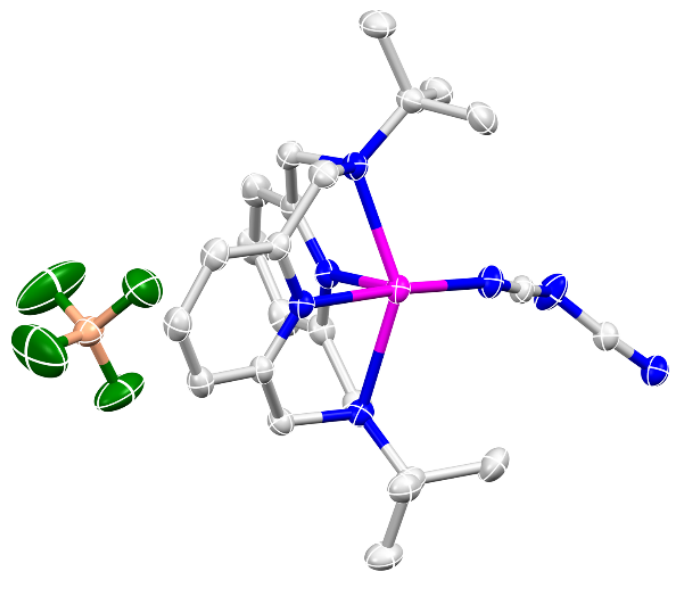

b)

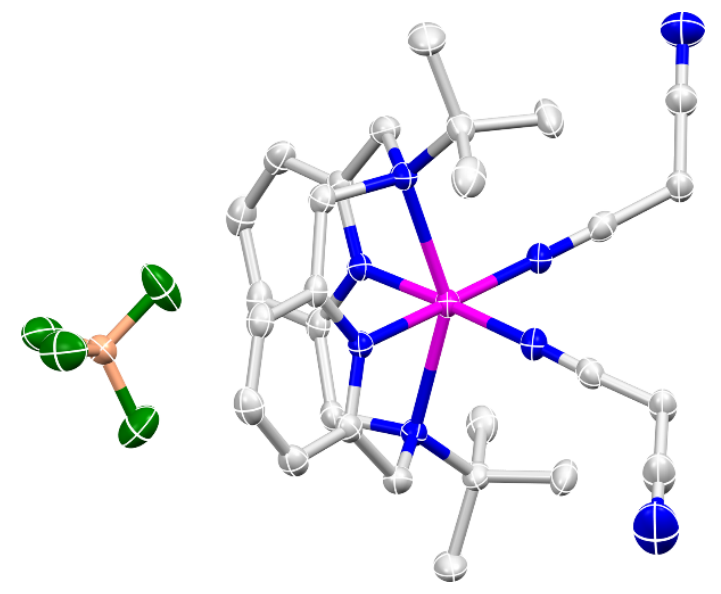

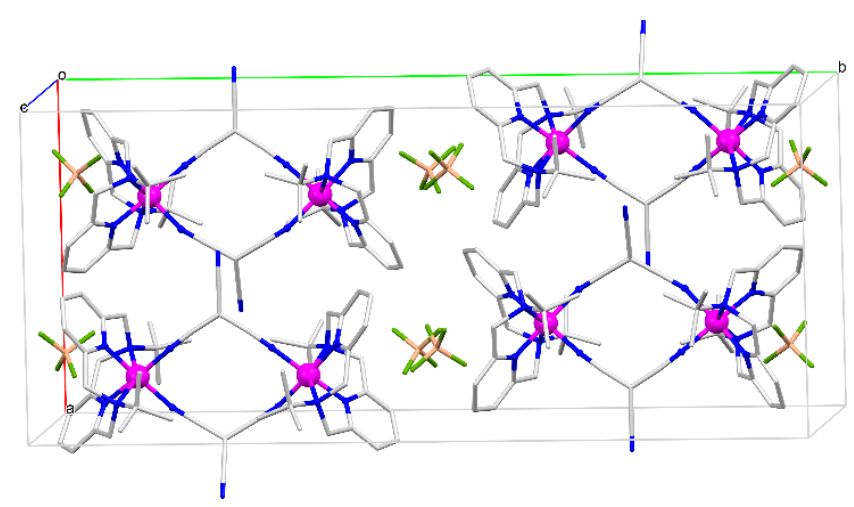

Figure S6 Top: Thermal ellipsoidal diagrams for the asymmetric units of the crystal structures of 1 (a) and 2 (b) at $296 \mathrm{~K}$. Thermal ellipsoids are drawn at a 25\% probability level. Bottom: Unit cell packing diagram of 2 at $100 \mathrm{~K}$. Hydrogen atoms are omitted for clarity. (Co: pink, C: grey, N: blue; B: light-pink; F: green, O: red) 

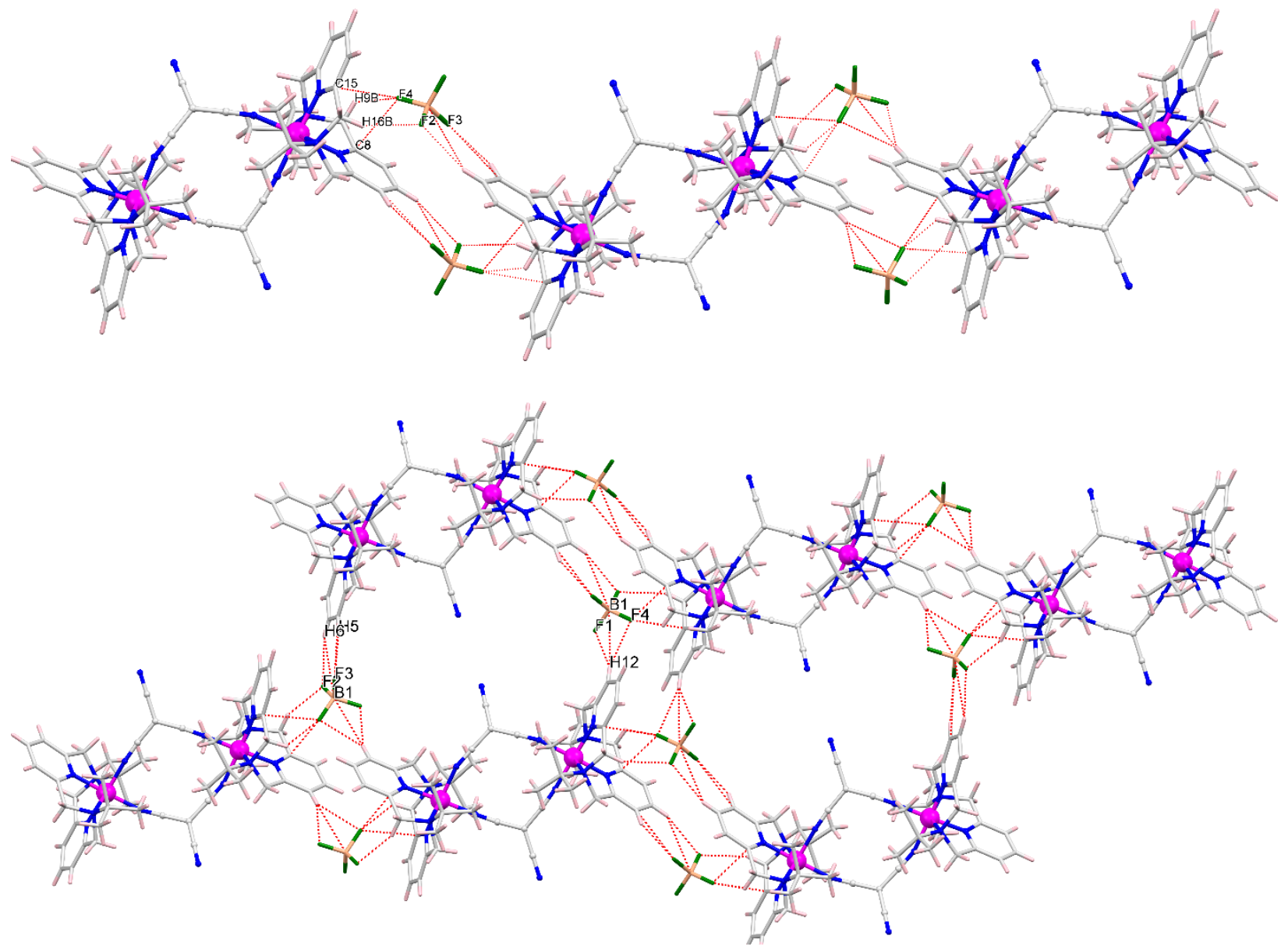

Figure S7 Packing diagrams of $\mathbf{2}$ at $100 \mathrm{~K}$ showing the 1D supramolecular arrangement (top) and the supramolecular double chain (bottom) connected by $\mathrm{C}-\mathrm{H} \cdots \mathrm{F}$ and $\mathrm{C} \cdots \cdots \mathrm{F}$ (red dotted lines) interactions.

(Co: pink, C: grey, N: blue; B: light-pink; F: green). 


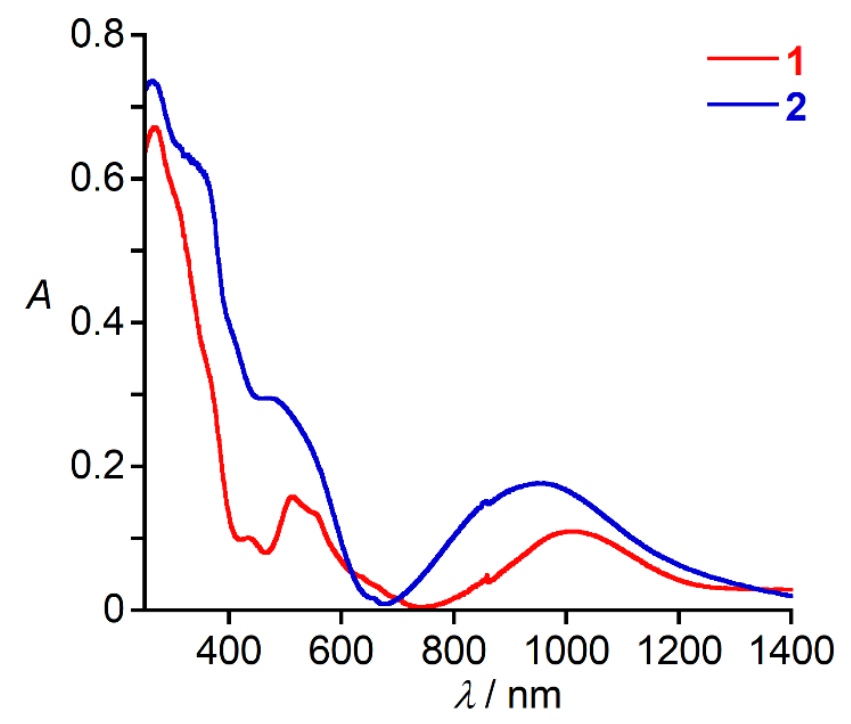

Figure S8 Solid state UV/vis/NIR spectra of $\mathbf{1}$ and $\mathbf{2}$ at RT.

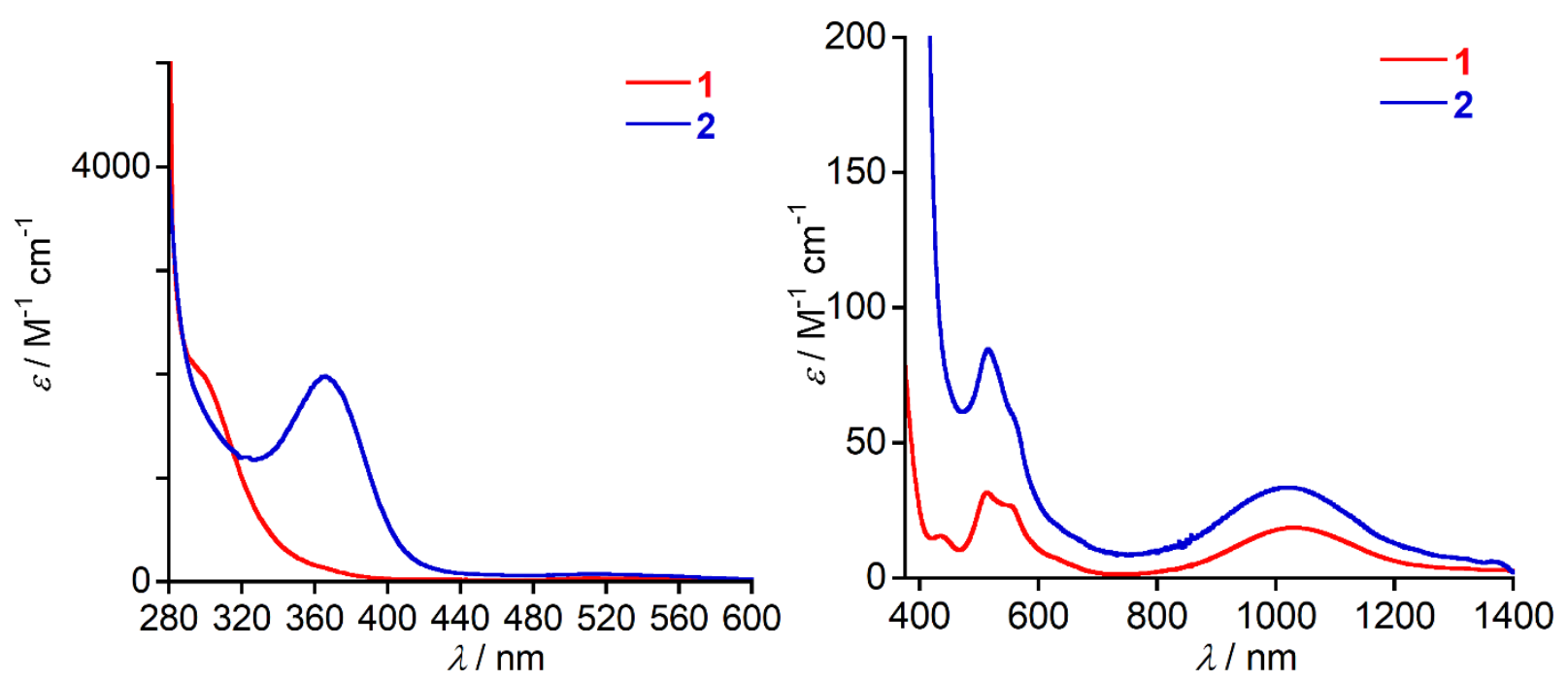

Figure S9 UV/vis/NIR spectra of $\mathbf{1}$ and $\mathbf{2}$ in DMF at room temperature (left: dilute solution, right: concentrated solution). 

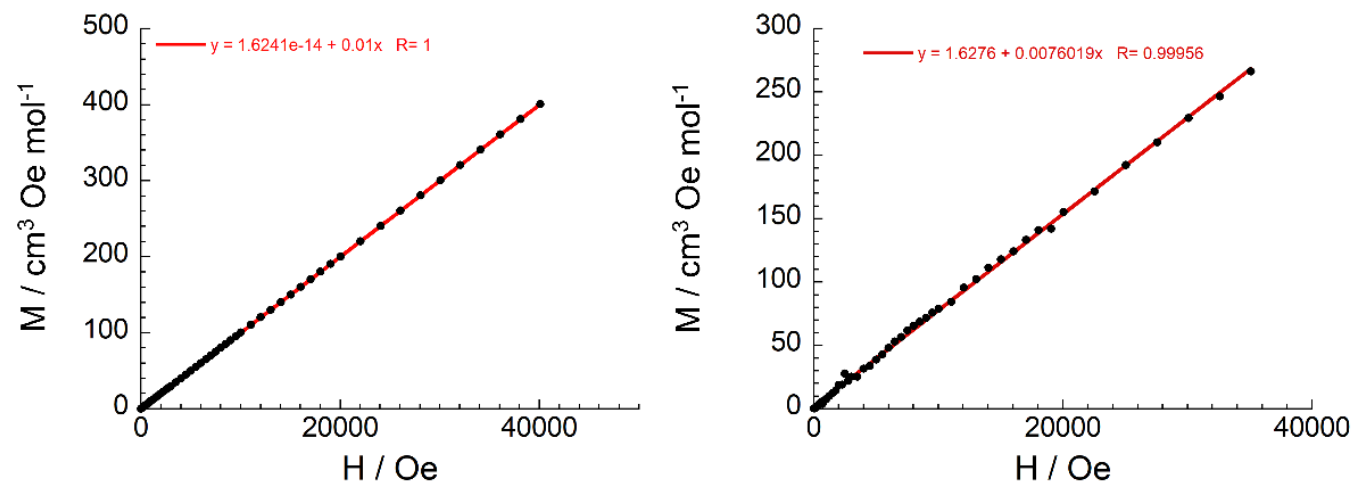

Figure S10. Field dependence of the magnetization as $M v_{s} H$ plots for $\mathbf{1}$ (left) and $\mathbf{2}$ (right) at $100 \mathrm{~K}$. The solid lines are best fit.
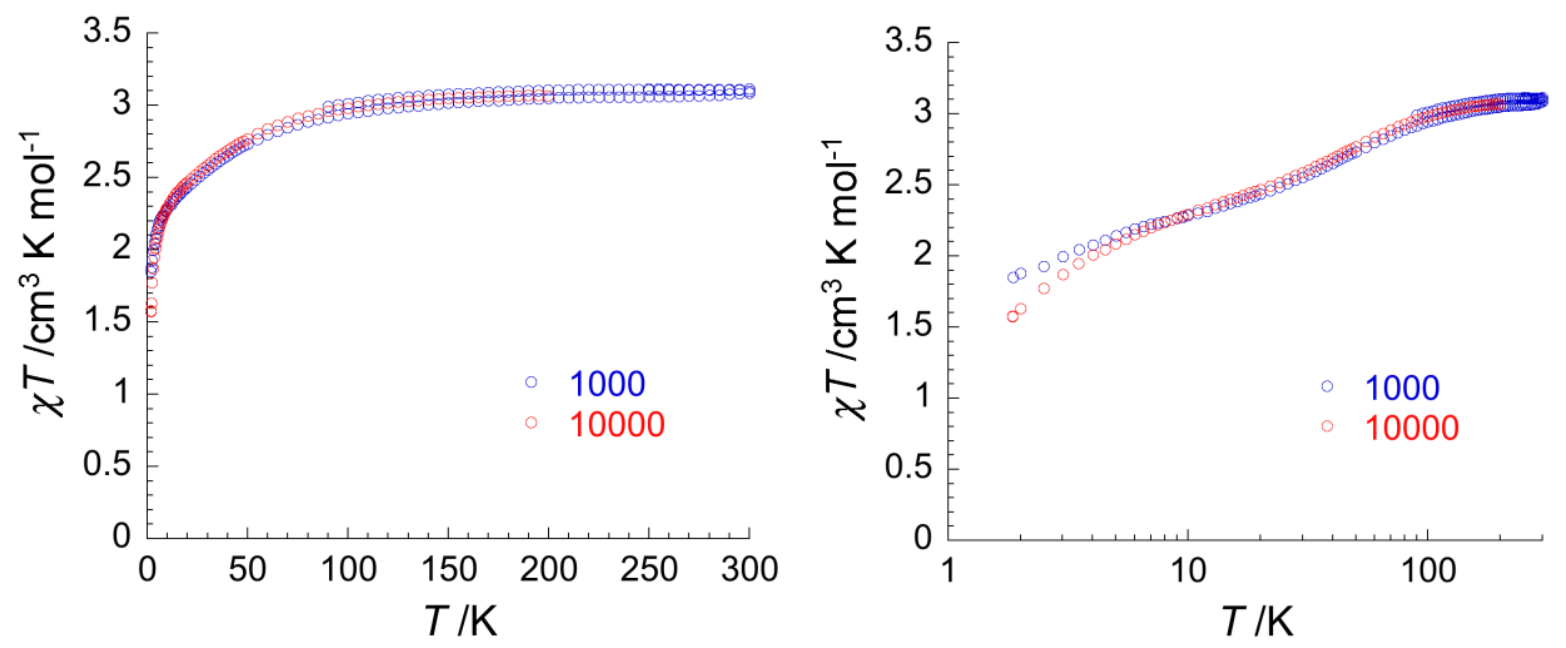

Figure S11 Temperature dependence of $\chi T$ product for 1 (left: normal Scale, right: log scale).
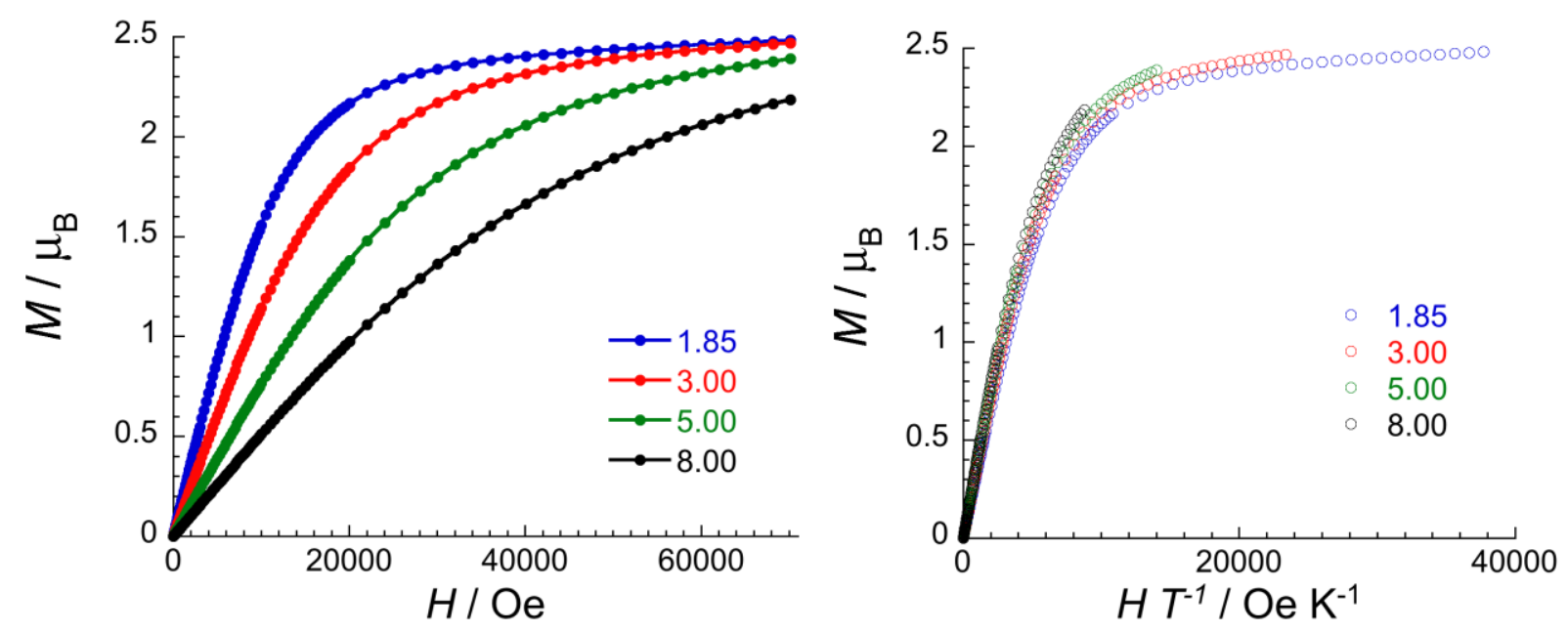

Figure S12 Field dependence of the magnetization as $M v s H$ (left) and $M v s H / T$ (right) plots for $\mathbf{1}$ at $1.85 \mathrm{~K}, 3 \mathrm{~K}, 5 \mathrm{~K}$ and $8 \mathrm{~K}$. The solid lines are guide for the eyes. 

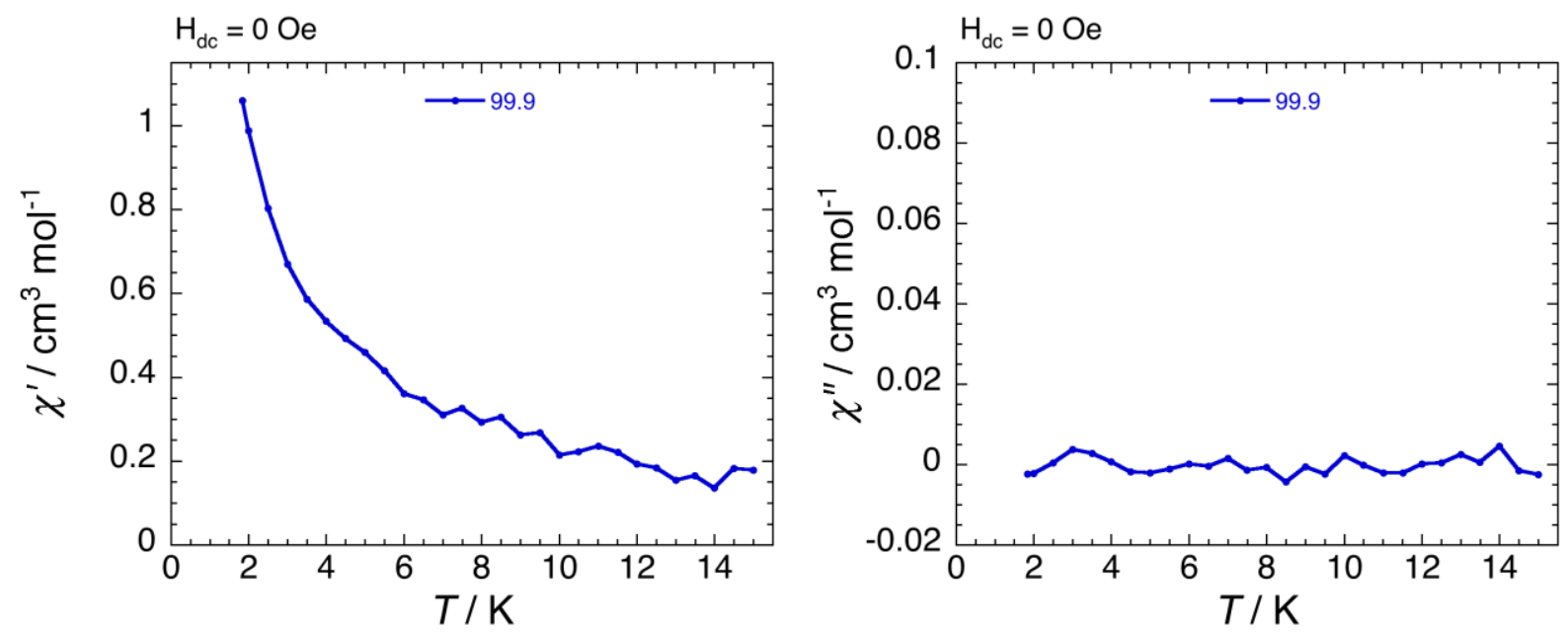

Figure S13 Frequency $(100 \mathrm{~Hz})$ vs temperature plot of the real $\left(\chi^{\prime}\right.$, left) and imaginary ( $\chi^{\prime \prime}$, right) components of the ac susceptibility at 0 Oe external dc field and different temperatures from $1.8-15 \mathrm{~K}$, respectively with a $3 \mathrm{Oe}$ ac field for a polycrystalline sample of $\mathbf{1}$.
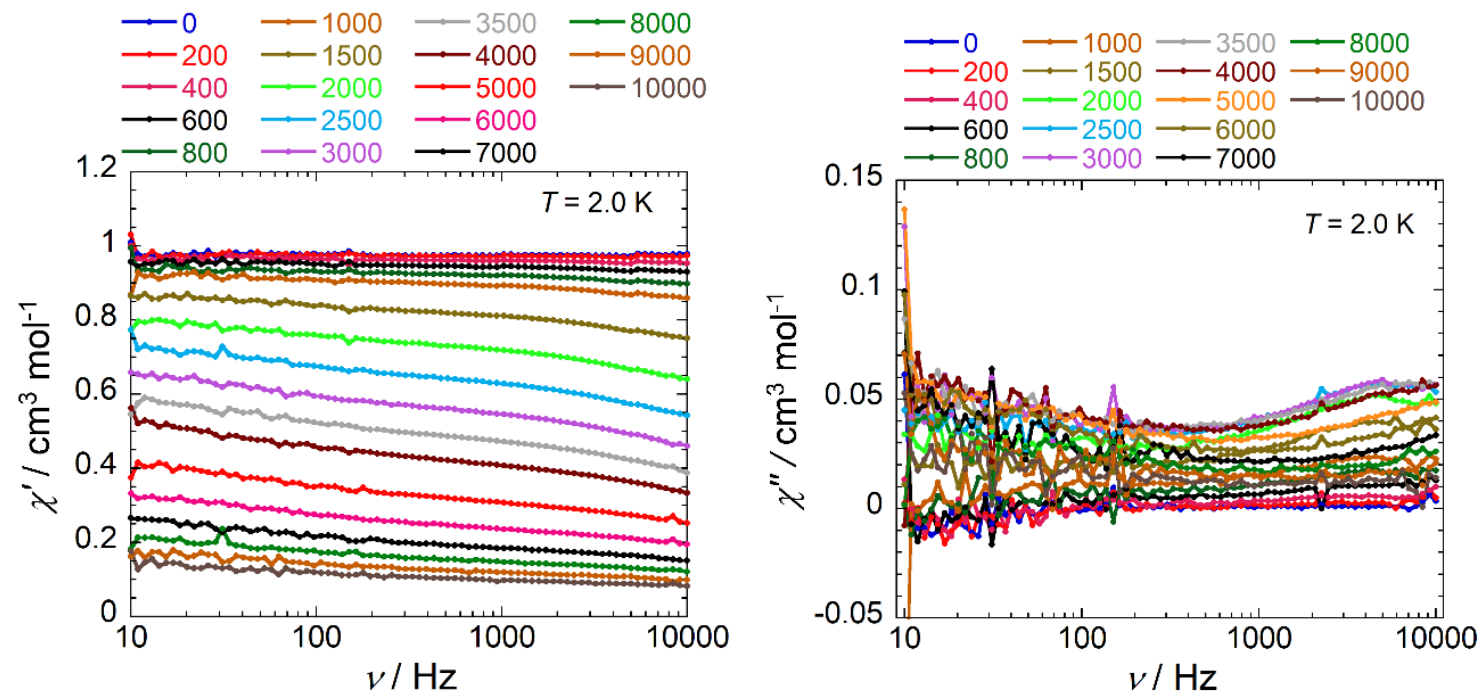

Figure S14 Frequency dependence of the real $\left(\chi^{\prime}\right.$, left $)$ and imaginary ( $\chi^{\prime \prime}$, right) parts of the ac susceptibility for a polycrystalline sample of 1 at $2 \mathrm{~K}$ at different dc-field between 0 and 10000 Oe. Solid lines are eye guide.

\section{Magnetic data fitting}

The experimental magnetic data of $\mathbf{1}$ have been treated with spin Hamiltonian in eq. 1 (main text) or with eq. 2 (main text) to encounter the zero-field splitting induced magnetic anisotropy of HS Co(II) ion. Both approached used the molecular field correction parameter $z j$, which means that iterative procedure must be applied to calculate the molar magnetization in given direction of the magnetic field as 


$$
M_{a}=-N_{\mathrm{A}} \frac{\sum_{i}\left(\sum_{k} \sum_{l} C_{i k}^{+}\left(Z_{a}\right)_{k l} C_{l i}\right) \exp \left(-\varepsilon_{a, i} / k T\right)}{\sum_{i} \exp \left(-\varepsilon_{a, i} / k T\right)}
$$

where $Z_{a}$ is the matrix element of the Zeeman term for the $a$-direction of the magnetic field and $C$ are the eigenvectors resulting from the diagonalization of the complete Hamiltonian matrix. Finally, to simulate experimental powder magnetization data, the integral (orientational) average of molar magnetization was calculated as $M_{\mathrm{mol}}=\frac{1}{4 \pi} \int_{0}^{2 \pi} \int_{0}^{\pi} M_{a} \sin \theta d \theta d \varphi$

All calculations were done with program POLYMAGNET. ${ }^{27}$

Details to Griffith-Figgis Hamiltonian in eq. 2:

In cobalt(II) (pseudo)octahedral complexes, the ${ }^{4} \mathrm{~F}$ atomic term is split into the ${ }^{4} \mathrm{~T}_{1 \mathrm{~g}}$ ground state, the first excited ${ }^{4} \mathrm{~T}_{2 \mathrm{~g}}$ state and the second excited ${ }^{4} \mathrm{~A}_{2 \mathrm{~g}}$ state. ${ }^{28}$ Thus, the ground state has an unquenched orbital angular momentum and the spin Hamiltonian formalism is invalid. The splitting of energy levels arising from the ${ }^{4} \mathrm{~T}_{1 \mathrm{~g}}$ state was analysed with the Hamiltonian based on Griffith ${ }^{29}$ and Figgis ${ }^{30}$ (eq.2), where $\Delta_{\mathrm{ax}}$ and $\Delta_{\text {rh }}$ measure splitting of the ${ }^{4} \mathrm{~T}_{1 \mathrm{~g}}$ ground term induced by lowering of the crystal-field symmetry, $\alpha$ is an orbital reduction factor, $\lambda$ is a spin-orbit coupling and $g_{\mathrm{e}}=2.0023$. The Hamiltonian utilizes $\mathrm{T}_{1}-\mathrm{P}$ isomorphism, thus the angular orbital momentum $L$ is equal to 1 with the effective Lande $g$-factor, $g_{L}=-\alpha$, and is applied to $\mid S, L, M_{S}, M_{L}>$ functions with $M_{L}=0, \pm 1$ and $M_{S}= \pm 1 / 2, \pm 3 / 2$. The orbital reduction factor integrates two parameters, $\alpha=A \kappa$, where $A$ is the Figgis coefficient of the configuration interaction resulting from the admixture of the excited terms reflecting the ligand field strength $(1<A<3 / 2)$, and $\kappa$ describes the lowering orbital contribution due to covalency of the metal-ligand bond and it usually holds $0.70<\kappa<1$. Furthermore, the spin-orbit coupling parameter $\lambda$ can be also reduced in comparison with its free-ion value $\lambda_{0}=-180 \mathrm{~cm}^{-1}$ due to the covalent character of the donor-acceptor bond. 

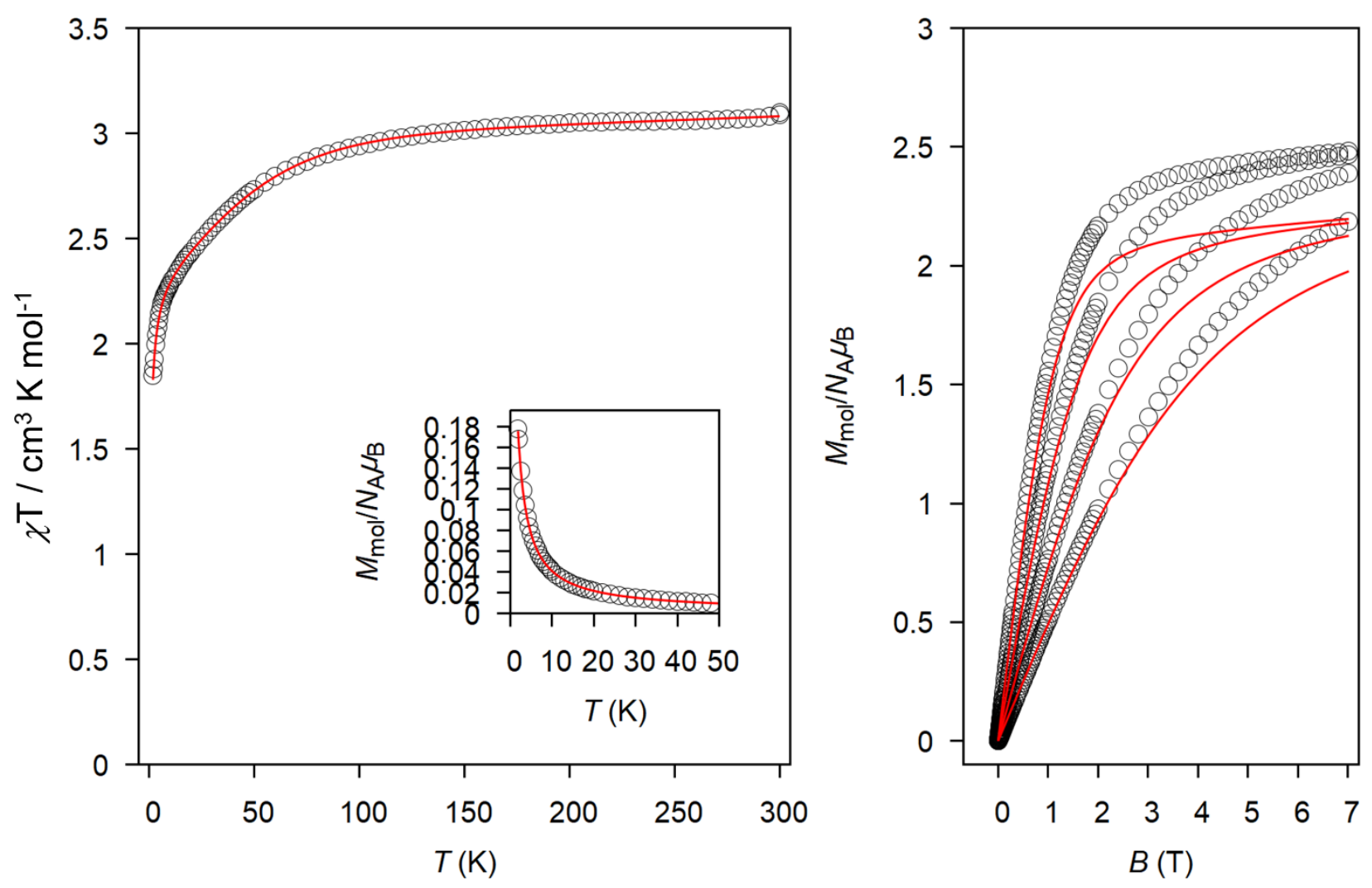

Figure S15 Magnetic data for 1 showed as temperature dependence of the $\chi T$ product (left) calculated from the molar magnetization measured at $H=0.1 \mathrm{~T}$ shown in the inset, and isothermal magnetizations measured at $T=1.85,3,5$ and $8 \mathrm{~K}$ (right). Empty circles - experimental data, full lines - calculated data with eq. 1 using $D=-72.3 \mathrm{~cm}^{-1}, E / D=0.00, g_{\mathrm{z}}=2.87, g_{\mathrm{xy}}=2.21$ and $z j=-0.273 \mathrm{~cm}^{-1}$. 

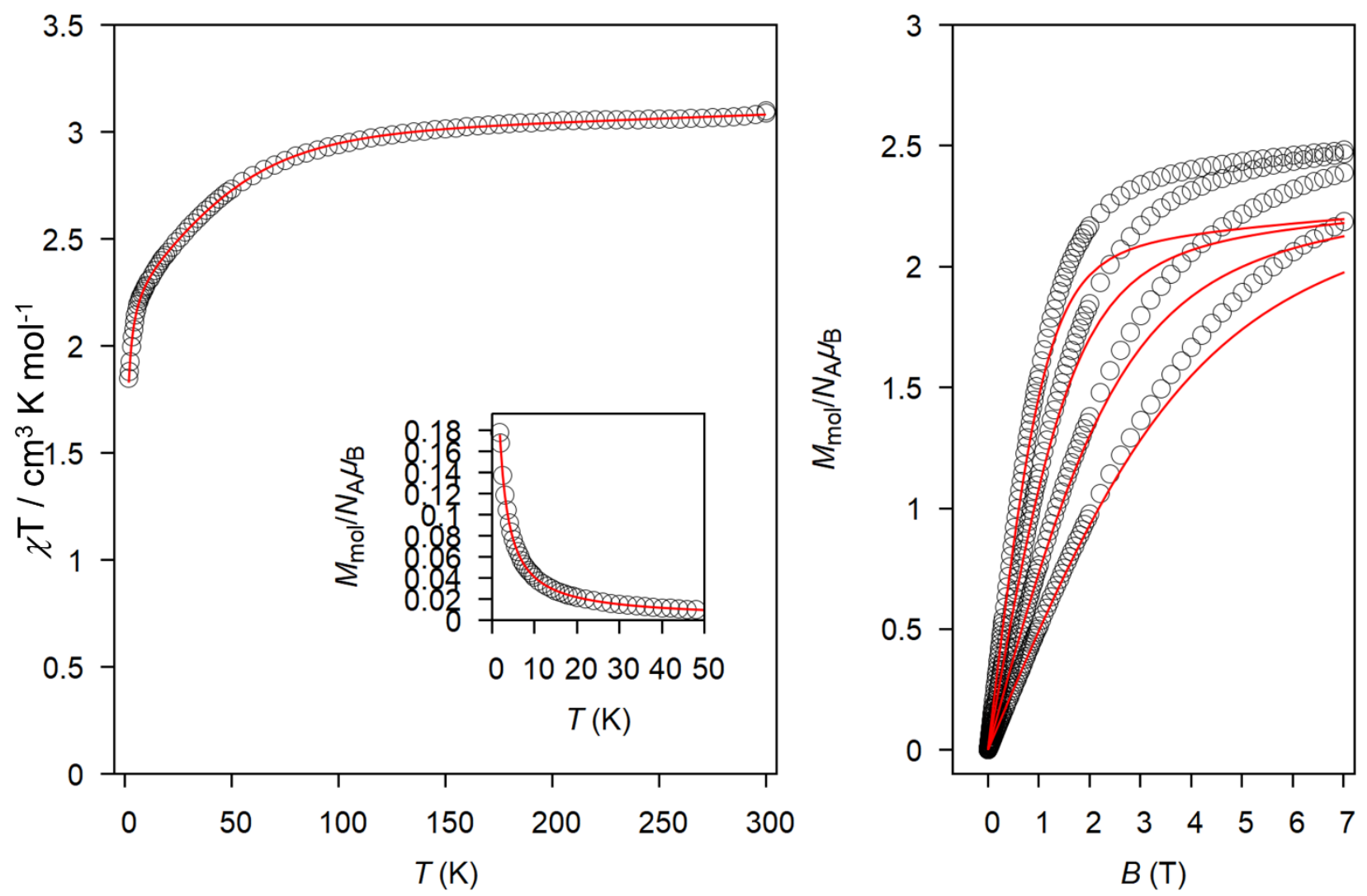

Figure S16 Magnetic data for 1 showed as temperature dependence of the $\chi T$ product (left) calculated from the molar magnetization measured at $H=0.1 \mathrm{~T}$ shown in the inset, and isothermal magnetizations measured at $T=1.85,3,5$ and $8 \mathrm{~K}$ (right). Empty circles - experimental data, full lines - calculated data with eq. 2 using $\Delta_{\alpha \mathrm{x}}=-1800 \mathrm{~cm}^{-1}, \Delta_{\mathrm{rh}}=-11.6 \mathrm{~cm}^{-1}, \alpha=1.50, \lambda=-135 \mathrm{~cm}^{-1}$ and $z j=-1.93 \mathrm{~cm}^{-1}$.

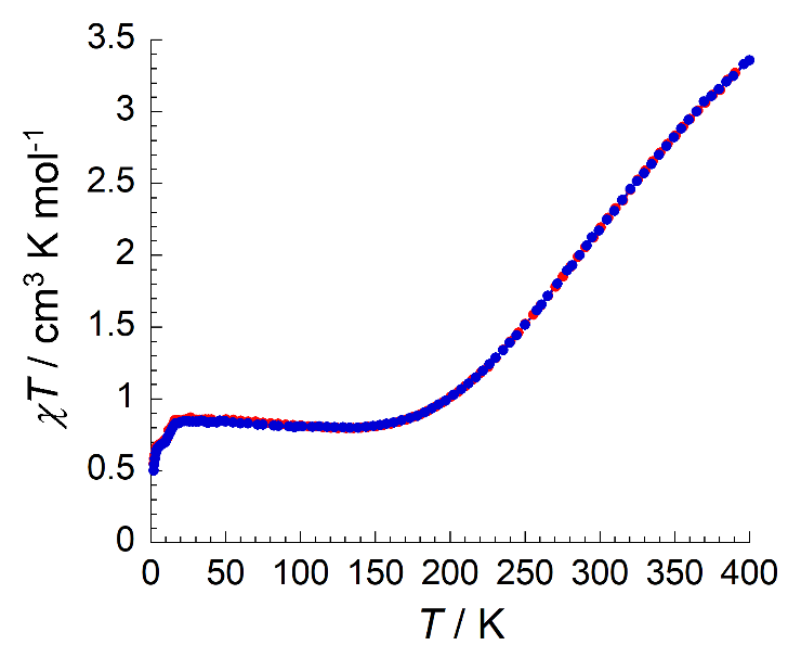

Figure S17 Temperature dependence of $\chi \mathrm{T}$ product for $\mathbf{2}$ in cooling (blue) and heating (red) modes. 
The following equation deduced from the ideal solution model was applied to fit the spin crossover properties of $\mathbf{2}$ observed by magnetic studies.

$$
X=X_{\mathrm{LS}}+\frac{x_{\mathrm{HS}}-X_{\mathrm{LS}}}{1+\exp \left[\Delta_{\mathrm{H}} / \mathrm{R}\left(1 / \mathrm{T}-1 / \mathrm{T}_{1 / 2}\right)\right]}
$$

$\mathrm{X}=\chi T$ product

$\mathrm{X}_{\mathrm{LS}}=\chi T$ product for pure low-spin

$\mathrm{X}_{\mathrm{HS}}=\chi T$ product for pure high-spin

$\Delta H=$ Enthalpy change associated to the spin crossover phenomenon

$R=$ Ideal gas constant

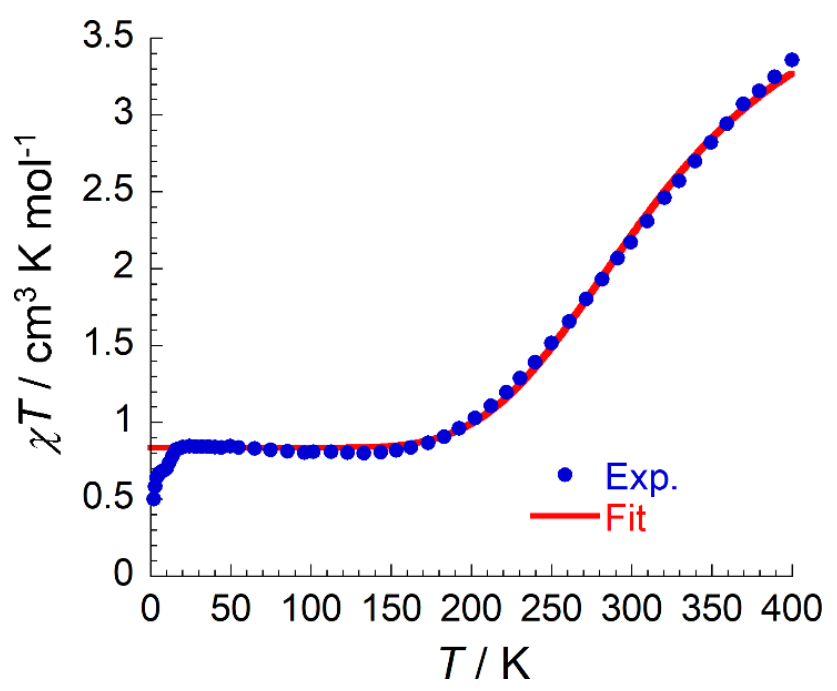

Figure S18 Fitting of $\chi T v s$ data of 2 using the ideal solution model.
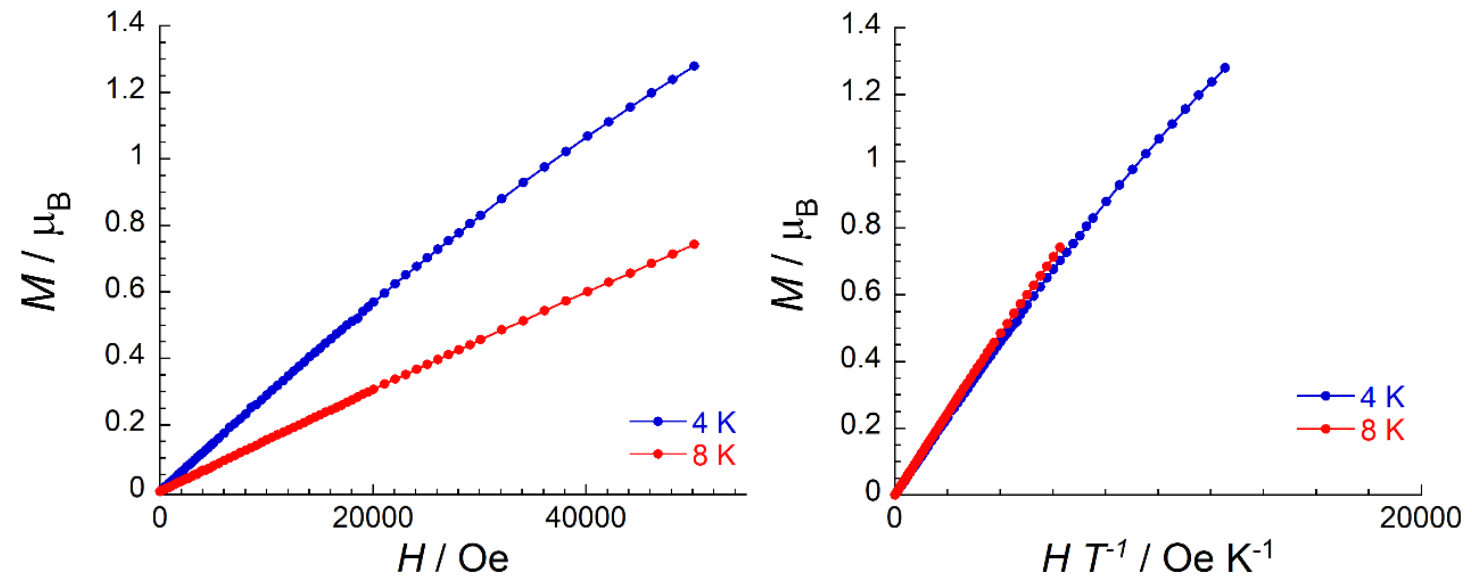

Figure S19 Field dependence of the magnetization as $M$ vs $H$ (left) and $M$ vs $H / T$ (right) plots for 2 at $4 \mathrm{~K}$ and $8 \mathrm{~K}$. The solid lines are guide for the eyes. 


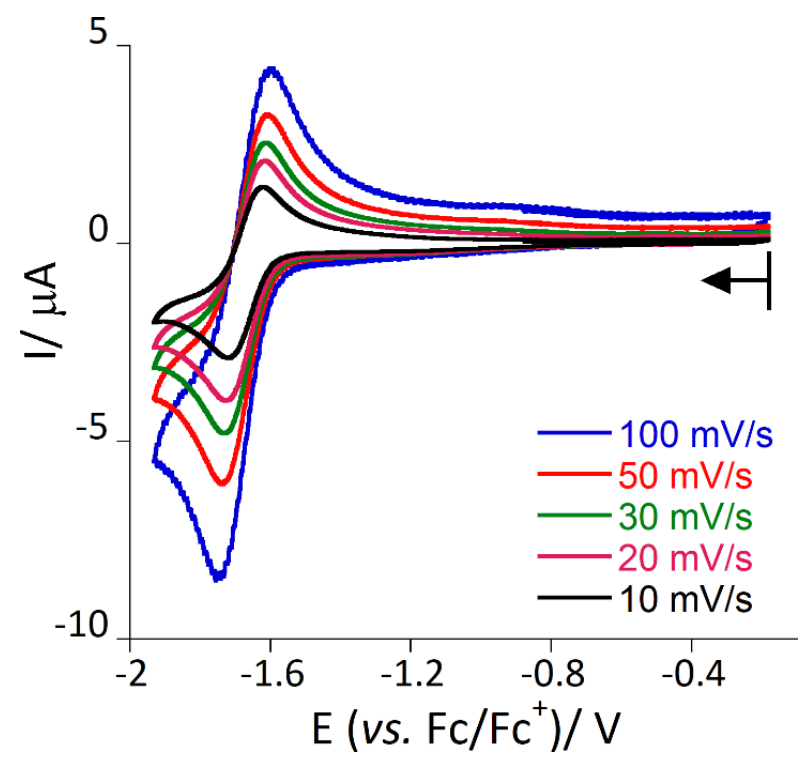

Figure S20 Cyclic voltammograms for the reduction (left) of $\mathbf{1}$ in $0.2 \mathrm{M}\left({ }^{n} \mathrm{Bu}_{4} \mathrm{~N}\right) \mathrm{PF}_{6} / \mathrm{DMF}$ at various scan rates. Arrows indicate the open circuit potential along with direction of potential sweep.

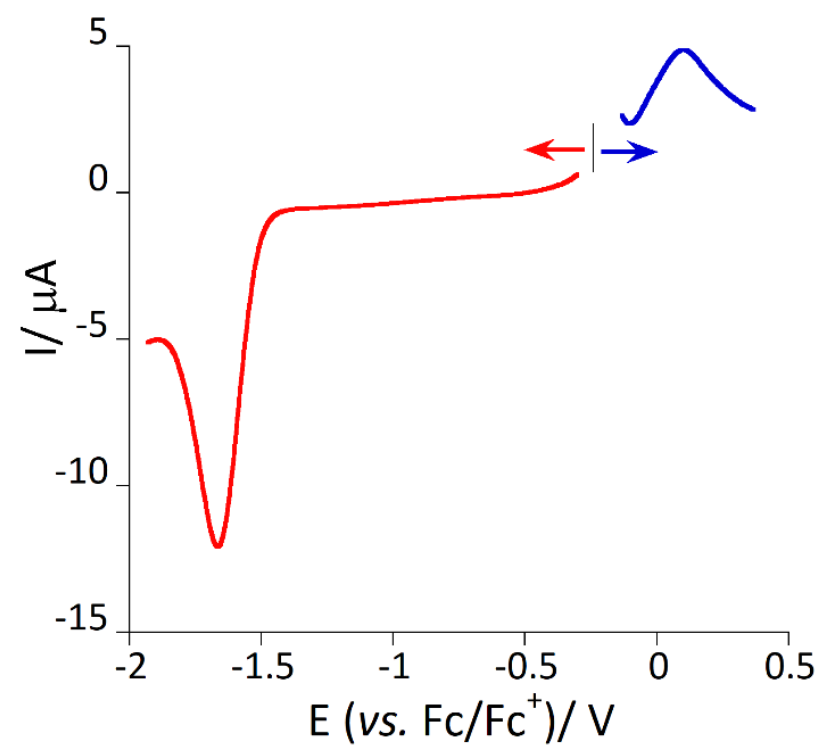

Figure S21 Square wave voltammograms (oxidation: blue line and reduction: red line) of 1 in $0.2 \mathrm{M}$ $\left({ }^{n} \mathrm{Bu}_{4} \mathrm{~N}\right) \mathrm{PF}_{6} / \mathrm{DMF}$. Arrows indicate the open circuit potential along with direction of potential sweep. 


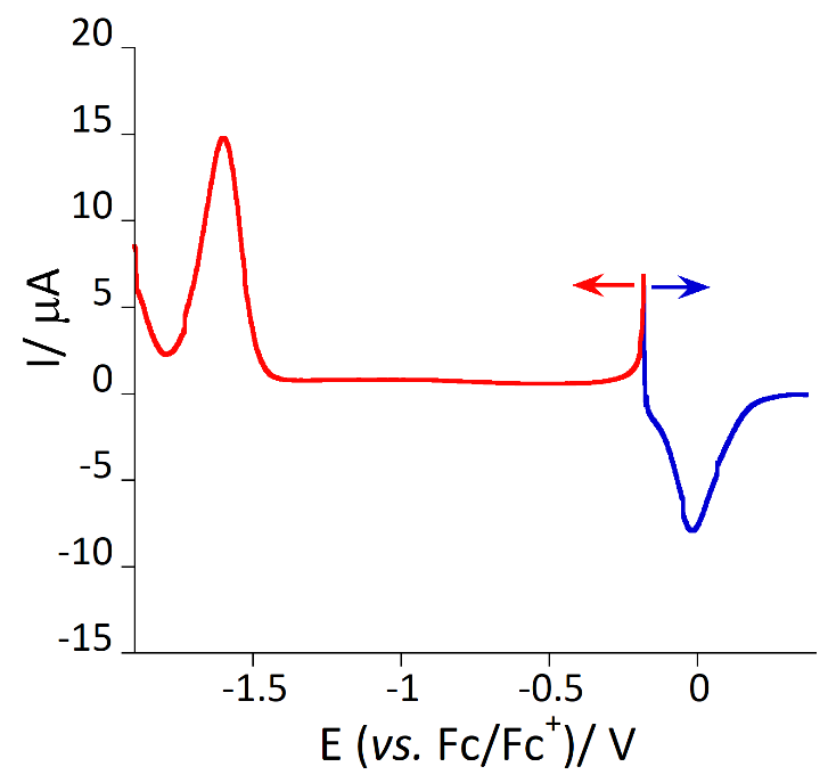

Figure S22 Differential pulse voltammograms (oxidation: blue line and reduction: red line) of $\mathbf{1}$ in $0.2 \mathrm{M}$ $\left({ }^{n} \mathrm{Bu}_{4} \mathrm{~N}\right) \mathrm{PF}_{6} / \mathrm{DMF}$. Arrows indicate the open circuit potential along with direction of potential sweep.

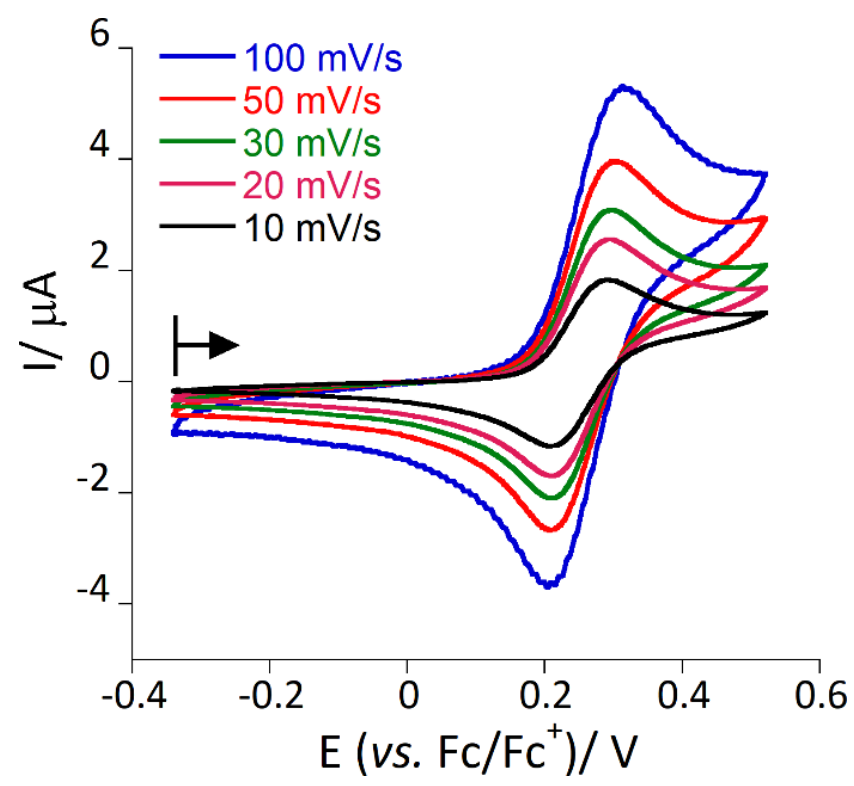

Figure S23 Cyclic voltammograms for the oxidation of 2 in $0.2 \mathrm{M}\left({ }^{n} \mathrm{Bu}_{4} \mathrm{~N}\right) \mathrm{PF}_{6} / \mathrm{DMF}$ at various scan rates. Arrows indicate the open circuit potential along with direction of potential sweep. 


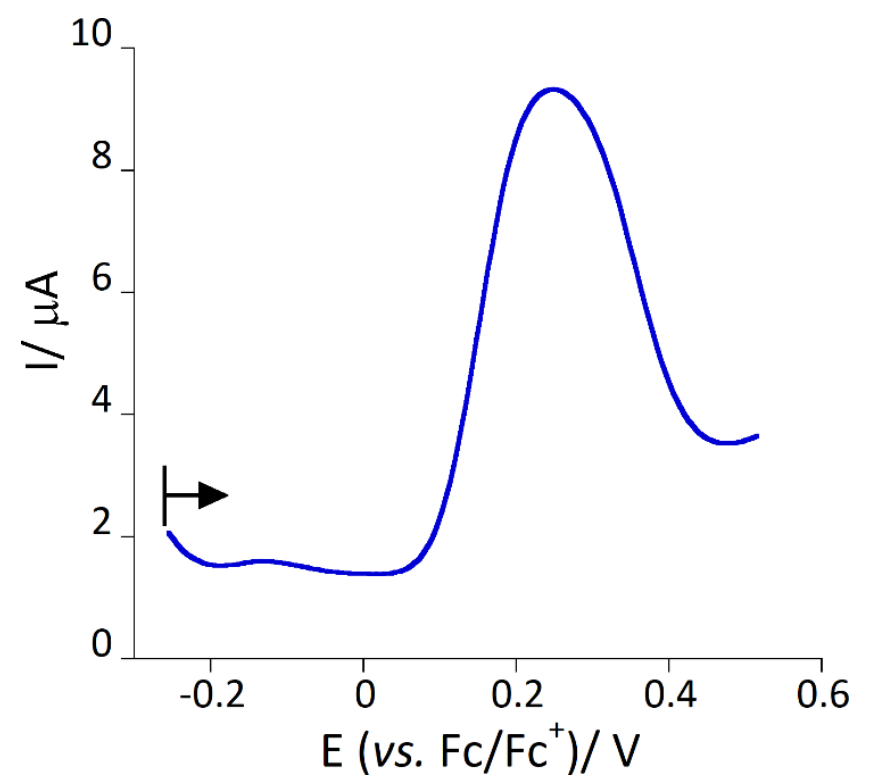

Figure S24 Square wave voltammogram for oxidation of 2 in $0.2 \mathrm{M}\left({ }^{n} \mathrm{Bu}_{4} \mathrm{~N}\right) \mathrm{PF}_{6} / \mathrm{DMF}$. Arrows indicate the open circuit potential along with direction of potential sweep.

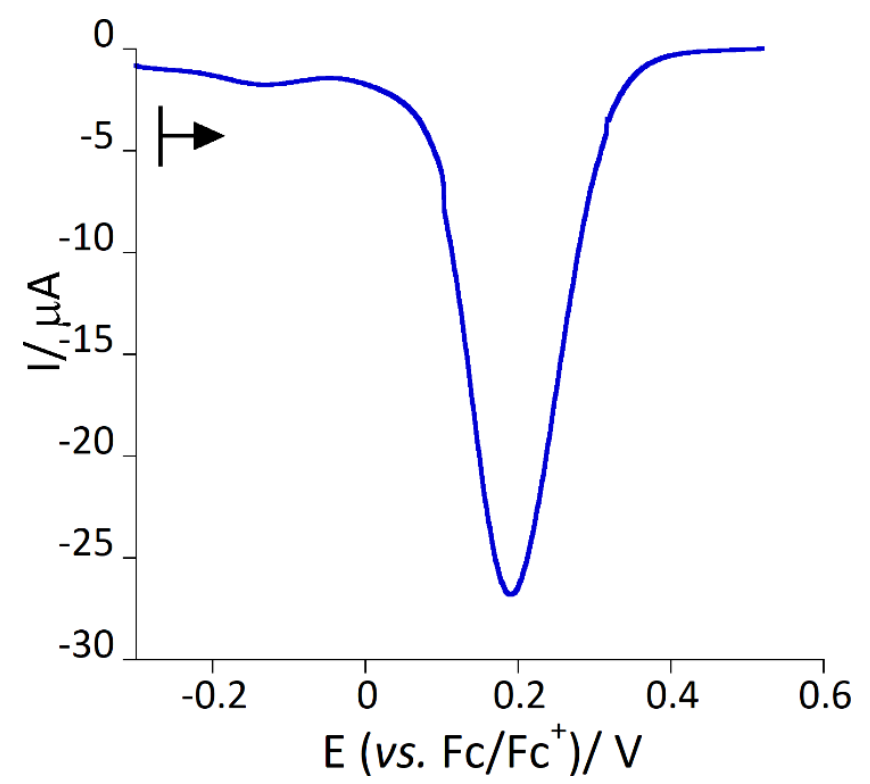

Figure S25 Differential pulse voltammogram for reduction of 2 in $0.2 \mathrm{M}\left({ }^{n} \mathrm{Bu}_{4} \mathrm{~N}\right) \mathrm{PF}_{6} / \mathrm{DMF}$. Arrows indicate the open circuit potential along with direction of potential sweep. 

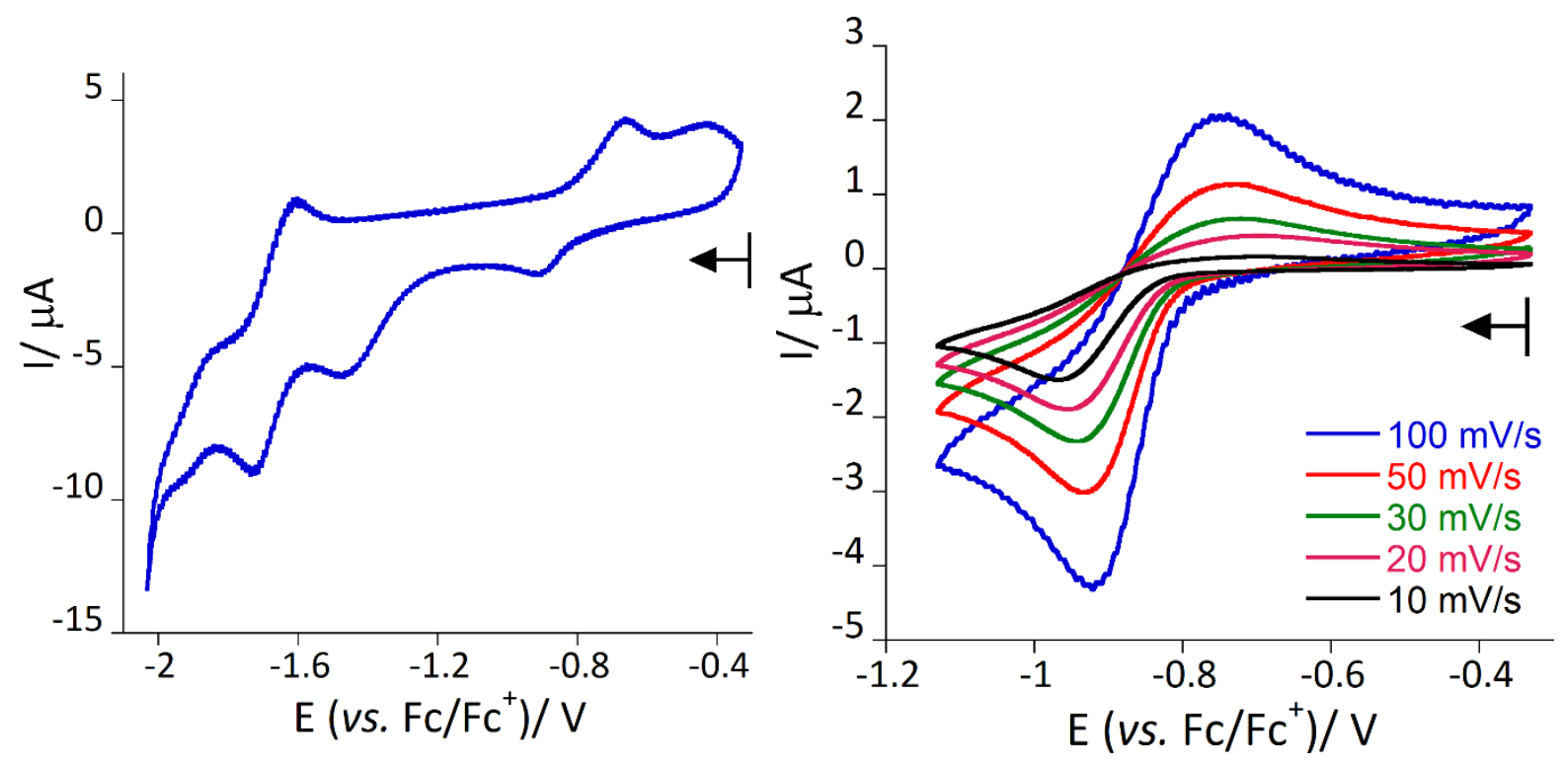

Figure S26 Left: Cyclic voltammogram for reduction of 2 in $0.2 \mathrm{M}\left({ }^{n} \mathrm{Bu}_{4} \mathrm{~N}\right) \mathrm{PF}_{6} / \mathrm{DMF}$ with sweep rate of $0.1 \mathrm{~V} / \mathrm{s}$; Right: Selected region $(0.35 \mathrm{~V}-1.2 \mathrm{~V})$ voltammograms with various sweep rates. Arrows indicate the open circuit potential along with direction of potential sweep.
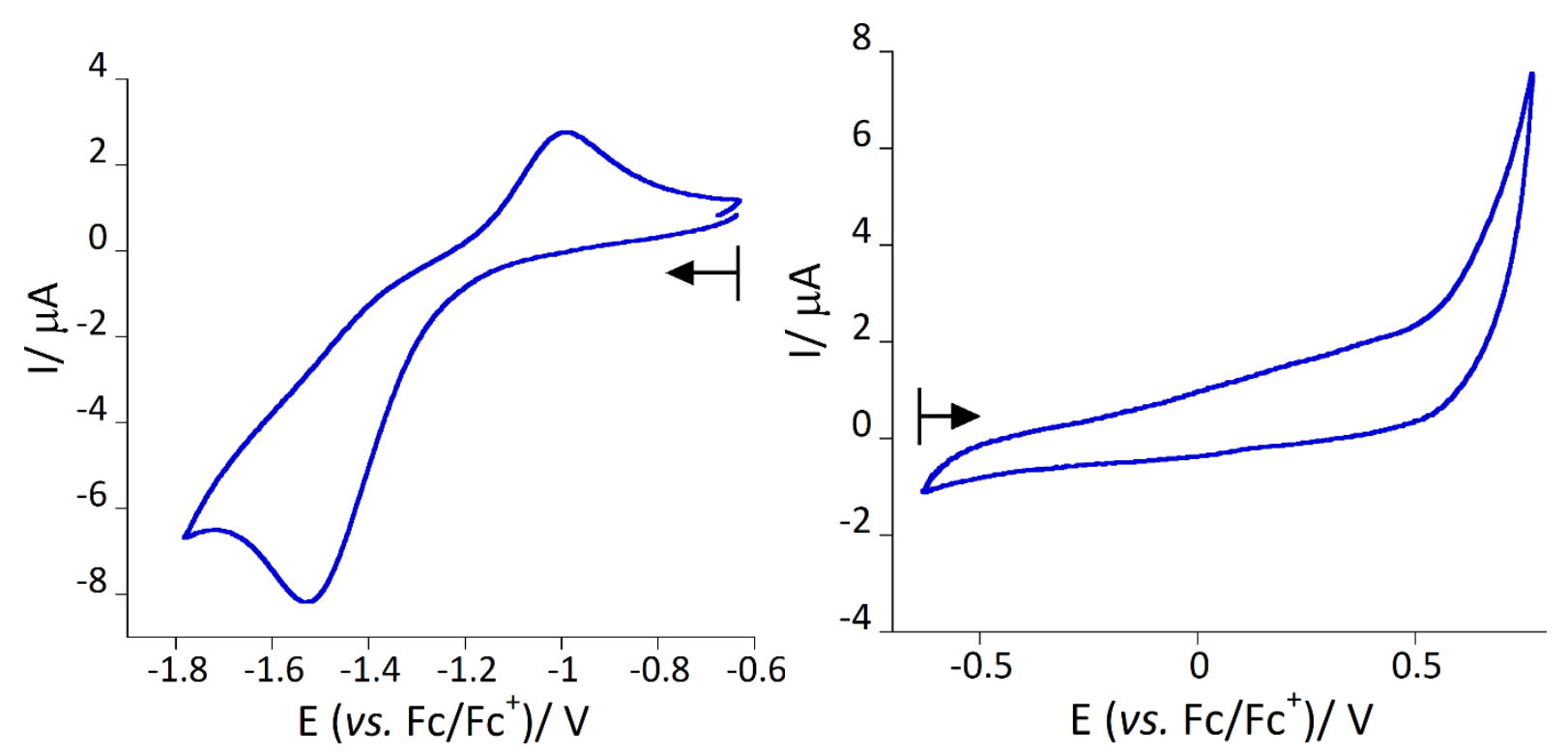

Figure S27 Cyclic voltammograms for the reduction (left) and oxidation (right) of the tetradentate ligand $\mathbf{L}$ in $0.2 \mathrm{M}\left({ }^{n} \mathrm{Bu}_{4} \mathrm{~N}\right) \mathrm{PF}_{6} / \mathrm{DMF}$ with scan rate of $100 \mathrm{mV} / \mathrm{s}$. 


\section{Theoretical Analyses}

In addition to B3LYP HS spin states spin isodensity surfaces of $\mathbf{1}$ and $\mathbf{2}$ showed in Figure 11 (main text), the broken-symmetry spin states are plotted with respective energy differences and spin projection values:

$\mathrm{BS}$ state of $\left[\mathrm{Co}_{2}(\mathbf{L})_{2}\left(\mathrm{~N}(\mathrm{CN})_{2}\right)_{3}\right]^{+}$of $\mathbf{1}$
$\begin{aligned} & \Delta=1.214 \mathrm{~cm}^{-1} \\ & <S^{2}>_{\mathrm{HS}}=12.0195\end{aligned}$
$<S^{2}>_{\mathrm{BS}}=3.0193$

Details to CASSCF calculation on $\left[\mathrm{Co}(\mathbf{L})\left(\mathrm{N}(\mathrm{CN})_{2}\right)_{2}\right]$ of $\mathbf{1}$ :

The $a b$ initio ligand field theory (AILFT) was used to calculate the energy of the d-orbitals as showed in Figure 13 (left, main text). In case of ideal $\mathrm{O}_{\mathrm{h}}$ point group symmetry, two sets of $t_{2 \mathrm{~g}}$ and $e_{\mathrm{g}}$ orbitals are expected, which is not the case in $\mathbf{1}$ due to non-homogenous ligand field and lower symmetry of the coordination polyhedra. Calculated quartet and doublet ligand-field terms originating from $3 \mathrm{~d}^{7}$ electron configuration are showed in Figure 13 (middle, main text), where the quartet is the ground state in agreement with high spin state of $\mathbf{1}$. The subsequent spin-orbit interaction leads to the ligand-field multiplets, hence the zero-field splitting of $S=3 / 2$, which is clearly visible in Figure 13 (right, main text). The large and negative $D$-parameter $\sim-100 \mathrm{~cm}^{-1}$ were calculated for $\mathbf{1}$. However, the calculated $g$-tensor and $D$-tensor parameters for this complex may not be fully valid due to the existence of the low-lying excited states (Figure 13), which limits the applicability of the spin Hamiltonian approach. Therefore, we have analysed the CASSCF/NEVPT2 and CASSCF/DCD-CAS(2) zero-field multiplet energy levels arising from the splitting of ${ }^{4} \mathrm{~T}_{1 \mathrm{~g}}$ ground term with the Griffith-Figgis Hamiltonian (eq (2)). ${ }^{31}$ The fitting the energies of the six lowest Kramer's doublets resulted in following parameters: $\alpha \cdot \lambda=-261 \mathrm{~cm}^{-1}, \Delta_{\mathrm{ax}}=-1121$ 
$\mathrm{cm}^{-1}, \Delta_{\mathrm{rh}}=-186 \mathrm{~cm}^{-1}$, and $\alpha \cdot \lambda=-251 \mathrm{~cm}^{-1}, \Delta_{\mathrm{ax}}=-1166 \mathrm{~cm}^{-1}, \Delta_{\mathrm{rh}}=-184 \mathrm{~cm}^{-1}$ with CASSCF/NEVPT2 and CASSCF/DCD-CAS(2), respectively.

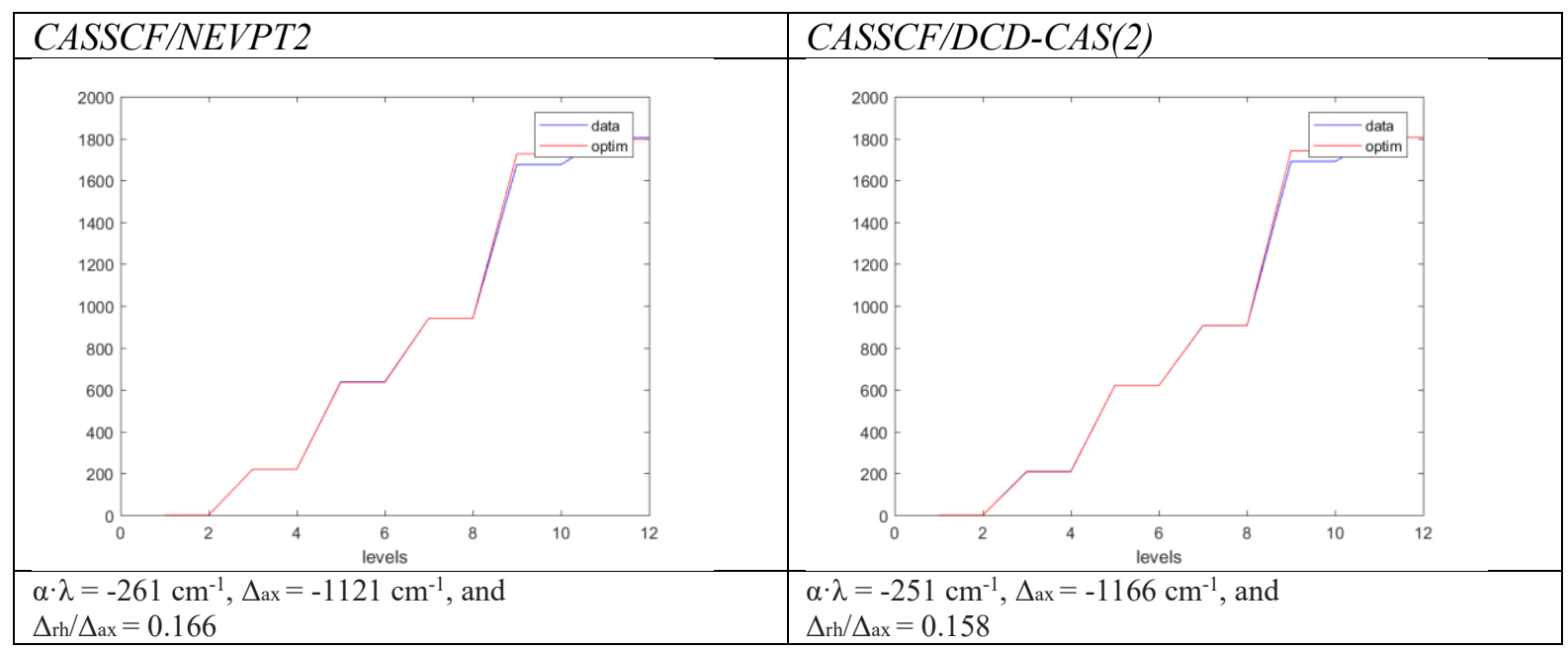

To summarize, both methods dealing with the dynamic electron correlation provided similar ZFS parameters and in general, there is good quantitative agreement with the parameters fitted from the experimental magnetic data of $\mathbf{1}$. 
Table S1. X-ray crystallography data for complexes $\mathbf{1}$ and $\mathbf{2}$.

\begin{tabular}{|c|c|c|c|}
\hline \multirow[b]{2}{*}{ CCDC no } & \multirow{2}{*}{2005150} & \multicolumn{2}{|c|}{2} \\
\hline & & 2005151 & 2005152 \\
\hline temp $(\mathrm{K})$ & 296 & 296 & 100 \\
\hline empirical formula & $\mathrm{C}_{25} \mathrm{H}_{36} \mathrm{BCoF}_{4} \mathrm{~N}_{7} \mathrm{O}$ & $\mathrm{C}_{52} \mathrm{H}_{64} \mathrm{~B}_{2} \mathrm{Co}_{2} \mathrm{~F}_{8} \mathrm{~N}_{14}$ & $\mathrm{C}_{52} \mathrm{H}_{64} \mathrm{~B}_{2} \mathrm{Co}_{2} \mathrm{~F}_{8} \mathrm{~N}_{14}$ \\
\hline formula wt & 596.35 & 1176.65 & 1176.65 \\
\hline cryst syst & Orthorhombic & Orthorhombic & Orthorhombic \\
\hline space group & Pbca & Pnma & Pnma \\
\hline$a(\AA)$ & $14.9953(16)$ & $13.9220(3)$ & $13.7843(4)$ \\
\hline$b(\AA)$ & $12.6583(13)$ & $32.8633(6)$ & $32.3571(9)$ \\
\hline$c(\AA)$ & $29.261(3)$ & $11.9927(2)$ & $11.9063(3)$ \\
\hline$\alpha(\operatorname{deg})$ & 90 & 90 & 90 \\
\hline$\beta(\operatorname{deg})$ & 90 & 90 & 90 \\
\hline$\gamma(\operatorname{deg})$ & 90 & 90 & 90 \\
\hline$V, \AA^{3}$ & $5554.2(10)$ & $5486.93(18)$ & $5310.4(3)$ \\
\hline$Z$ & 8 & 8 & 8 \\
\hline$d_{\text {calcd }}\left(\mathrm{g} \mathrm{cm}^{-3}\right)$ & 1.426 & 1.424 & 1.472 \\
\hline$\mu\left(\mathrm{mm}^{-1}\right)$ & 0.677 & 0.682 & 0.705 \\
\hline$F(000)$ & 2488 & 2440 & 2440 \\
\hline$\theta_{\max }(\mathrm{deg})$ & 30.684 & 28.596 & 30.382 \\
\hline completeness $(\%)$ & 99.7 & 86.7 & 99.7 \\
\hline no. of. rflns collected & 8583 & 6194 & 8118 \\
\hline no. of. Indep rflns & 4679 & 3370 & 5860 \\
\hline goodness of fit on $F^{2}$ & 1.022 & 1.040 & 1.027 \\
\hline final $\mathrm{R}$ indices $(I>2 \sigma(\mathrm{I}))$ & $\mathrm{R} 1=0.0578$ & $\mathrm{R} 1=0.0513$ & $\mathrm{R} 1=0.0418$ \\
\hline & $\mathrm{wR} 2=0.1765$ & $\mathrm{wR} 2=0.1368$ & $\mathrm{wR} 2=0.1023$ \\
\hline final $\mathrm{R}$ indices (all data) & $\mathrm{R} 1=0.1523$ & $\mathrm{R} 1=0.1229$ & $\mathrm{R} 1=0.0694$ \\
\hline 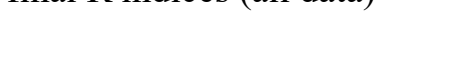 & $\mathrm{wR} 2=0.1942$ & $w R 2=0.1632$ & $w R 2=0.1162$ \\
\hline Largest diff. peak/hole / e $\AA^{-3}$ & $0.53 /-0.69$ & $0.44 /-0.52$ & $0.41 /-0.79$ \\
\hline
\end{tabular}


Table S2 Selected bond lengths $(\AA)$ and bond angles $\left({ }^{\circ}\right)$ in $\mathbf{1}$ and $\mathbf{2}$.

\begin{tabular}{|c|c|c|c|c|}
\hline \multicolumn{2}{|c|}{1} & \multicolumn{3}{|c|}{2} \\
\hline & $296 \mathrm{~K}$ & & $296 \mathrm{~K}$ & $100 \mathrm{~K}$ \\
\hline $\mathrm{Co}(1)-\mathrm{N}(1)$ & $2.349(3)$ & $\operatorname{Co}(1)-\mathrm{N}(1)$ & $2.318(3)$ & $2.311(2)$ \\
\hline $\mathrm{Co}(1)-\mathrm{N}(2)$ & $2.042(3)$ & $\mathrm{Co}(1)-\mathrm{N}(2)$ & $1.950(3)$ & $1.911(2)$ \\
\hline $\mathrm{Co}(1)-\mathrm{N}(3)$ & $2.310(3)$ & $\mathrm{Co}(1)-\mathrm{N}(3)$ & $2.323(3)$ & $2.322(2)$ \\
\hline $\mathrm{Co}(1)-\mathrm{N}(4)$ & $2.044(2)$ & $\mathrm{Co}(1)-\mathrm{N}(4)$ & $1.943(3)$ & $1.917(2)$ \\
\hline $\mathrm{Co}(1)-\mathrm{N}(5)$ & $2.100(3)$ & $\mathrm{Co}(1)-\mathrm{N}(5)$ & $1.989(3)$ & $1.918(2)$ \\
\hline $\mathrm{Co}(1)-\mathrm{N}(6)$ & $2.067(3)$ & $\mathrm{Co}(1)-\mathrm{N}(6)$ & $1.959(3)$ & $1.949(2)$ \\
\hline $\mathrm{N}(1)-\mathrm{Co}(1)-\mathrm{N}(2)$ & $75.2(1)$ & $\mathrm{N}(1)-\mathrm{Co}(1)-\mathrm{N}(2)$ & $80.4(1)$ & $78.38(6)$ \\
\hline $\mathrm{N}(1)-\mathrm{Co}(1)-\mathrm{N}(3)$ & $144.15(9)$ & $\mathrm{N}(1)-\mathrm{Co}(1)-\mathrm{N}(3)$ & $149.25(9)$ & $151.09(6)$ \\
\hline $\mathrm{N}(1)-\mathrm{Co}(1)-\mathrm{N}(4)$ & $78.09(9)$ & $\mathrm{N}(1)-\mathrm{Co}(1)-\mathrm{N}(4)$ & $77.5(1)$ & $81.13(6)$ \\
\hline $\mathrm{N}(1)-\mathrm{Co}(1)-\mathrm{N}(5)$ & $95.7(1)$ & $\mathrm{N}(1)-\mathrm{Co}(1)-\mathrm{N}(5)$ & $104.5(1)$ & $96.78(7)$ \\
\hline $\mathrm{N}(1)-\mathrm{Co}(1)-\mathrm{N}(6)$ & $105.8(1)$ & $\mathrm{N}(1)-\mathrm{Co}(1)-\mathrm{N}(6)$ & $97.1(1)$ & $104.03(7)$ \\
\hline $\mathrm{N}(2)-\mathrm{Co}(1)-\mathrm{N}(3)$ & $79.0(1)$ & $\mathrm{N}(2)-\mathrm{Co}(1)-\mathrm{N}(3)$ & $77.7(1)$ & $81.15(6)$ \\
\hline $\mathrm{N}(2)-\mathrm{Co}(1)-\mathrm{N}(4)$ & $87.3(1)$ & $\mathrm{N}(2)-\mathrm{Co}(1)-\mathrm{N}(4)$ & $88.8(1)$ & $89.35(7)$ \\
\hline $\mathrm{N}(2)-\mathrm{Co}(1)-\mathrm{N}(5)$ & $87.4(1)$ & $\mathrm{N}(2)-\mathrm{Co}(1)-\mathrm{N}(5)$ & $92.9(1)$ & $89.59(7)$ \\
\hline $\mathrm{N}(2)-\mathrm{Co}(1)-\mathrm{N}(6)$ & $178.9(1)$ & $\mathrm{N}(2)-\mathrm{Co}(1)-\mathrm{N}(6)$ & $177.4(1)$ & $176.74(7)$ \\
\hline $\mathrm{N}(3)-\mathrm{Co}(1)-\mathrm{N}(4)$ & $76.2(1)$ & $\mathrm{N}(3)-\mathrm{Co}(1)-\mathrm{N}(4)$ & $80.6(1)$ & $78.43(6)$ \\
\hline $\mathrm{N}(3)-\mathrm{Co}(1)-\mathrm{N}(5)$ & $107.7(1)$ & $\mathrm{N}(3)-\mathrm{Co}(1)-\mathrm{N}(5)$ & $98.0(1)$ & $103.29(7)$ \\
\hline $\mathrm{N}(3)-\mathrm{Co}(1)-\mathrm{N}(6)$ & $99.9(1)$ & $\mathrm{N}(3)-\mathrm{Co}(1)-\mathrm{N}(6)$ & $104.3(1)$ & $97.35(7)$ \\
\hline $\mathrm{N}(4)-\mathrm{Co}(1)-\mathrm{N}(5)$ & $172.7(1)$ & $\mathrm{N}(4)-\mathrm{Co}(1)-\mathrm{N}(5)$ & $177.6(1)$ & $177.81(7)$ \\
\hline $\mathrm{N}(4)-\mathrm{Co}(1)-\mathrm{N}(6)$ & $92.6(1)$ & $\mathrm{N}(4)-\mathrm{Co}(1)-\mathrm{N}(6)$ & $89.9(1)$ & $93.19(7)$ \\
\hline $\mathrm{N}(5)-\mathrm{Co}(1)-\mathrm{N}(6)$ & $92.7(1)$ & $\mathrm{N}(5)-\mathrm{Co}(1)-\mathrm{N}(6)$ & $88.5(1)$ & $87.95(7)$ \\
\hline $\mathrm{Co}(1)-\mathrm{N}(5)-\mathrm{C}(1)$ & $156.0(3)$ & $\mathrm{Co}(1)-\mathrm{N}(5)-\mathrm{C}(1)$ & $157.6(3)$ & $157.2(2)$ \\
\hline $\mathrm{Co}(1)-\mathrm{N}(6)-\mathrm{C}(2)$ & $177.2(2)$ & $\mathrm{Co}(1)-\mathrm{N}(6)-\mathrm{C}(2)$ & $169.7(3)$ & $170.7(2)$ \\
\hline $\mathrm{N}(5)-\mathrm{C}(1)-\mathrm{N}(7)$ & $173.7(4)$ & $\mathrm{N}(5)-\mathrm{C}(1)-\mathrm{C}(25)$ & $175.4(4)$ & $175.0(2)$ \\
\hline $\mathrm{N}(6)-\mathrm{C}(2)-\mathrm{N}(8)$ & $173.7(4)$ & $\mathrm{N}(6)-\mathrm{C}(2)-\mathrm{C}(27)$ & $177.0(4)$ & $177.1(2)$ \\
\hline
\end{tabular}




\section{Continuous Shape Measures (CShM) Analysis:}

Continuous Shape Measures (CShM) analysis was carried out to determine the geometry around cobalt center. Based on the values obtained, the idealized polyhedron was matched with the actual coordination spheres. The smallest value is symbolic of proximity of actual coordination sphere and idealized polyhedron.

Table S3 CShM analysis data for complexes $\mathbf{1}$ and $\mathbf{2 .}$

\begin{tabular}{|l|l|l|l|l|c|c|}
\hline Complex & Temp. & \multicolumn{5}{|c|}{ Structure } \\
\cline { 3 - 7 } & & HP - 6 & PPY - 6 & OC - 6 & TPR - 6 & JPPY - 6 \\
\hline $\mathbf{1}$ & $296 \mathrm{~K}$ & 32.861 & 22.211 & $\mathbf{2 . 8 4 5}$ & 10.503 & 26.893 \\
\hline $\mathbf{2}$ & $296 \mathrm{~K}$ & 33.362 & 24.258 & $\mathbf{2 . 3 6 5}$ & 12.305 & 29.207 \\
\cline { 3 - 7 } & $100 \mathrm{~K}$ & 33.487 & 25.480 & $\mathbf{2 . 2 7 7}$ & 12.837 & 29.794 \\
\hline
\end{tabular}

HP - 6: Hexagon (D6h), PPY - 6 = Pentagonal pyramid, OC - 6: Octahedron (Oh), TPR - 6: Trigonal prism (D3h), JPPY $-6=$ Johnson pentagonal pyramid J2 (C5v);

\section{Octahedral distortion parameters:}

$\sum$ is the sum of the deviation from $90^{\circ}$ of the 12 cis-angles of the $\mathrm{CoN}_{6}$ octahedron; $\Theta$ is the sum of the deviation from $60^{\circ}$ of the 24 trigonal angles of the projection of the $\mathrm{CoN}_{6}$ octahedron onto the trigonal faces; $\zeta$ is the distance distortion parameter, which is the sum of deviation from individual M-N bond distances with respect to the mean metal-ligand bond distance. 
Table S4 Short intra- and inter molecular interactions in $\mathbf{1}$ and $\mathbf{2}$.

\begin{tabular}{|c|c|c|c|c|c|c|}
\hline Complex & $\mathrm{T} / \mathrm{K}$ & $\mathrm{D}-\mathrm{H} \cdots \mathrm{A}$ & D-H / Å & $\mathrm{H} \cdots \mathrm{A} / \AA$ & $\mathrm{D} \cdots \mathrm{A} / \AA$ & $\angle \mathrm{D}-\mathrm{H} \cdots \mathrm{A} /{ }^{\circ}$ \\
\hline 1 & 296 & 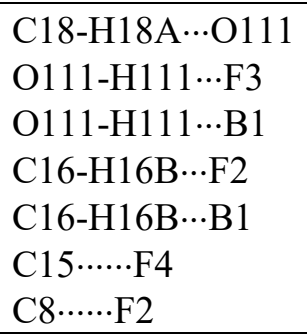 & $\begin{array}{l}1.11 \\
0.82 \\
0.82 \\
0.97 \\
0.97 \\
- \\
-\end{array}$ & $\begin{array}{l}2.64 \\
1.862 \\
3.131 \\
2.53 \\
3.10 \\
- \\
-\end{array}$ & $\begin{array}{l}3.377(8) \\
2.674(4) \\
3.922(7) \\
3.461(3) \\
3.939(5) \\
3.139(5) \\
3.148(4)\end{array}$ & $\begin{array}{l}124(3) \\
170.3 \\
163.0 \\
160(2) \\
145(2) \\
- \\
-\end{array}$ \\
\hline \multirow[t]{2}{*}{2} & 296 & 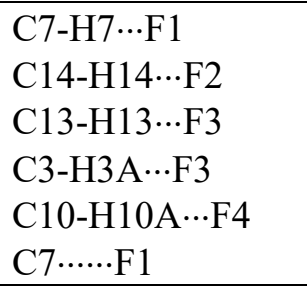 & $\begin{array}{l}0.931 \\
0.930 \\
0.930 \\
0.970 \\
0.970 \\
-\end{array}$ & $\begin{array}{l}2.356 \\
2.461 \\
2.634 \\
2.529 \\
2.611 \\
-\end{array}$ & $\begin{array}{l}3.228(4) \\
3.148(5) \\
3.524(5) \\
3.424(4) \\
3.289(5) \\
3.886(5)\end{array}$ & $\begin{array}{l}155.9 \\
130.7 \\
160.3 \\
153.4 \\
127.1 \\
-\end{array}$ \\
\hline & 100 & 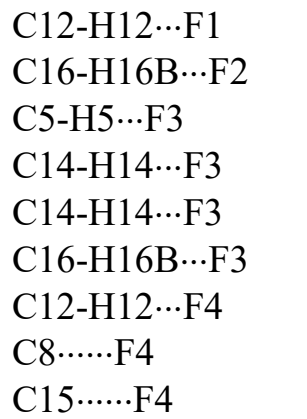 & $\begin{array}{l}0.930 \\
0.970 \\
0.930 \\
0.930 \\
0.970 \\
0.970 \\
0.930 \\
- \\
-\end{array}$ & $\begin{array}{l}2.344 \\
2.489 \\
2.437 \\
2.608 \\
2.655 \\
2.438 \\
2.616 \\
- \\
-\end{array}$ & $\begin{array}{l}3.215(2) \\
3.401(2) \\
3.111(2) \\
3.383(2) \\
3.279(2) \\
3.311(2) \\
3.371(2) \\
2.999(2) \\
3.111(2)\end{array}$ & $\begin{array}{l}155.8 \\
156.5 \\
129.4 \\
141.2 \\
141.2 \\
149.5 \\
138.7 \\
- \\
-\end{array}$ \\
\hline
\end{tabular}




\section{References}

1. Meneghetti, S. P.; Lutz, P. J.; Fischer, J.; Kress, J. Synthesis and X-ray structure of a monoprotonated salt and of three transition-metal complexes of N,N'-ditertiobutyl-2,11diaza[3.3](2,6)pyridinophane. Polyhedron 2001, 20, 2705-2710.

2. Ghosh, S.; Selvamani, S.; Mehta, S.; Mondal, A. Reversible thermo-induced spin crossover in a mononuclear cis-dicyanamido-cobalt(ii) complex containing a macrocyclic tetradentate ligand. Dalton Trans. 2020, 49, 9208-9212.

3. Degen, T.; Sadki, M.; Bron, E.; König, U.; Nénert, G. The HighScore suite. Powder Diffr. 2014, 29, S13-S18.

4. Sheldrick, G. M. SADABS Version 2.03, Bruker Analytical X-Ray Systems, Madison, WI, USA, 2000.

5. Sheldrick, G. Crystal structure refinement with SHELXL. Acta Crystallogr., Sect. C: Struct. Chem 2015, 71, 3-8.

6. Neese, F. Software update: the ORCA program system, version 4.0. WIREs Comput Mol Sci. 2018, $8, \mathrm{e} 1327$.

7. Neese, F. The ORCA program system. WIREs Comput Mol Sci. 2012, 2, 73-78.

8. Becke, A. D. Density-functional exchange-energy approximation with correct asymptotic behavior. Phys. Rev. A 1988, 38, 3098-3100.

9. $\quad$ Stephens, P. J.; Devlin, F. J.; Chabalowski, C. F.; Frisch, M. J. Ab Initio Calculation of Vibrational Absorption and Circular Dichroism Spectra Using Density Functional Force Fields. J. Phys. Chem. 1994, 98, 11623-11627.

10. Lee, C.; Yang, W.; Parr, R. G. Development of the Colle-Salvetti correlation-energy formula into a functional of the electron density. Phys. Rev. B 1988, 37, 785-789.

11. Soda, T.; Kitagawa, Y.; Onishi, T.; Takano, Y.; Shigeta, Y.; Nagao, H.; Yoshioka, Y.; Yamaguchi, $\mathrm{K}$. Ab initio computations of effective exchange integrals for $\mathrm{H}-\mathrm{H}, \mathrm{H}-\mathrm{He}-\mathrm{H}$ and $\mathrm{Mn} 2 \mathrm{O} 2$ complex: comparison of broken-symmetry approaches. Chem. Phys. Lett. 2000, 319, 223-230.

12. Weigend, F.; Ahlrichs, R. Balanced basis sets of split valence, triple zeta valence and quadruple zeta valence quality for $\mathrm{H}$ to Rn: Design and assessment of accuracy. Phys. Chem. Chem. Phys. 2005, 7, 3297-3305.

13. Weigend, F. Accurate Coulomb-fitting basis sets for H to Rn. Phys. Chem. Chem. Phys. 2006, 8, 1057-1065.

14. Izsák, R.; Neese, F. An overlap fitted chain of spheres exchange method. J. Chem. Phys. 2011, 135, 144105.

15. Neese, F.; Wennmohs, F.; Hansen, A.; Becker, U. Efficient, approximate and parallel Hartree-Fock and hybrid DFT calculations. A 'chain-of-spheres' algorithm for the Hartree-Fock exchange. Chem. Phys. 2009, 356, 98-109.

16. Momma, K.; Izumi, F. VESTA 3 for three-dimensional visualization of crystal, volumetric and morphology data. J. Appl. Crystallogr. 2011, 44, 1272-1276.

17. Malmqvist, P.-Å.; Roos, B. O. The CASSCF state interaction method. Chem. Phys. Lett. 1989, 155, 189-194.

18. Angeli, C.; Cimiraglia, R.; Malrieu, J.-P. n-electron valence state perturbation theory: A spinless formulation and an efficient implementation of the strongly contracted and of the partially contracted variants. J. Chem. Phys. 2002, 117, 9138-9153.

19. Angeli, C.; Cimiraglia, R.; Evangelisti, S.; Leininger, T.; Malrieu, J.-P. Introduction of n-electron valence states for multireference perturbation theory. J. Chem. Phys. 2001, 114, 10252-10264.

20. Ganyushin, D.; Neese, F. First-principles calculations of zero-field splitting parameters. J. Chem. Phys. 2006, 125, 024103.

21. Neese, F. Efficient and accurate approximations to the molecular spin-orbit coupling operator and their use in molecular g-tensor calculations. J. Chem. Phys. 2005, 122, 034107. 
22. Maurice, R.; Bastardis, R.; Graaf, C. d.; Suaud, N.; Mallah, T.; Guihéry, N. Universal Theoretical Approach to Extract Anisotropic Spin Hamiltonians. J. Chem. Theory Comput. 2009, 5, 2977-2984.

23. Hellweg, A.; Hättig, C.; Höfener, S.; Klopper, W. Optimized accurate auxiliary basis sets for RIMP2 and RI-CC2 calculations for the atoms Rb to Rn. Theor. Chem. Acc. 2007, 117, 587-597.

24. Singh, S. K.; Eng, J.; Atanasov, M.; Neese, F. Covalency and chemical bonding in transition metal complexes: An ab initio based ligand field perspective. Coord. Chem. Rev. 2017, 344, 2-25.

25. Mingos, D. M. P.; Day, P.; Dahl, J. P. Molecular Electronic Structures of Transition Metal Complexes II. Springer Berlin: Berlin, 2014.

26. Pathak, S.; Lang, L.; Neese, F. A dynamic correlation dressed complete active space method: Theory, implementation, and preliminary applications. J. Chem. Phys. 2017, 147, 234109.

27. Herchel, R.; Boča, R. Program POLYMAGNET 2006-2020,

28. Figgis, B. N.; Hitchman, M. A. Ligand field theory and its applications. Wiley-VCH: New York, 2000.

29. Griffith, J. S. The theory of transition-metal ions. Cambridge University Press: Cambridge, 2009.

30. Figgis, B. N.; Gerloch, M.; Lewis, J.; Mabbs, F. E.; Webb, G. A. The magnetic behaviour of cubicfield 4T1g terms in lower symmetry. J. Chem. Soc. A 1968, 2086-2093.

31. Nemec, I.; Herchel, R.; Trávníček, Z. Two polymorphic Co(ii) field-induced single-ion magnets with enormous angular distortion from the ideal octahedron. Dalton Trans. 2018, 47, 1614-1623. 